\title{
SOUND DESIGN EM GAMES E UX: ESTUDO DE CASO DA RELAÇÃO ENTRE EFEITOS SONOROS E AÇÕES DE JOGO NO SUPER MARIO BROS
}

\author{
SOUND DESIGN IN GAMES AND UX: A CASE STUDY OF THE \\ RELATIONSHIP BETWEEN SOUND EFFECTS AND GAME ACTIONS IN \\ SUPER MARIO BROS
}

\author{
Marisa Sel Franco ${ }^{1}$, Bach. \\ marisafranco@gmail.com \\ Felipe Raposo ${ }^{2}$, Bach. \\ epiloke@gmail.com \\ João Vitor Vale², Bach. \\ jv.vale.marques@gmail.com \\ Flávia Carvalho ${ }^{2}$, Bach. \\ flvdcrvlh@gmail.com \\ André Demaison ${ }^{2}$, M.Sc.
}

demaison@gmail.com e http://orcid.org/0000-0003-3629-3477
${ }^{1}$ [HiPES] High Performance and Efficient Systems/Departamento de Informática, Universidade Federal do Paraná, Curitiba, Brasil
${ }^{2}$ Núcleo de Prototipagem e Design - Fabrique, Universidade Federal do Maranhão, São Luís, Brasil

sound design, experiência do usuário, efeitos sonoros, jogos eletrônicos

\begin{abstract}
Considerados como mídias interativas, os jogos eletrônicos têm suas características sonoras como fortes auxiliadoras para se obter uma UX (experiência de usuário) expandida: quer como feedback de ações dos jogadores ou como elemento construtor da atmosfera imersiva. As interfaces auditivas são pontes de comunicação designer-usuário que extrapolam os elementos visuais das telas. Os efeitos sonoros e trilhas têm ainda um papel importante para construção identitária do jogo, possibilitando ao jogador ter pleno conhecimento das ações. O presente trabalho buscou avaliar a capacidade do usuário de identificar ações do jogo apenas por seus respectivos efeitos sonoros, com o objetivo de estudar o papel do sound design na UX. Para isso, optou-se pelo estudo de caso da interface sonora do jogo Super Mario Bros., lançado pela Nintendo para o console NES, em 1985, e que deu origem a uma das mais importantes franquias de games da história. O estudo é relevante para o desenvolvimento de novos projetos sonoros em videogames, principalmente levando em consideração a possibilidade de se trabalhar aspectos inclusivos por meio da interface
\end{abstract} sonora.

sound design, user experience (UX), sound effects, video games

Considered as interactive media, electronic games have their sound features as strong support to obtain an expanded UX (user experience): as a feedback of the players' actions or as a constructive element of the immersive atmosphere. The auditive interfaces are bridges of the designer-user communication which extrapolate the screen's visual elements. Sound effects and soundtracks have yet an important role to the game identity construction, enabling the player to have full knowledge of the actions. This essay sought to evaluate the user's ability to identify the game actions only through its respective sound effects, aiming to study the sound design role in the UX. To that, it was opted for the case study of the sound interface of the game Super Mario Bros., released by Nintendo to the NES console, in 1985, which gave birth to one of the most important game franchises of the history. The study is relevant for the development of new sound projects in video games, mainly taking into account the possibility of working inclusive aspects through the sound interface.

DOI: $\underline{\text { http://dx.doi.org/10.22570/ergodesignhci.v8i2.1460 }}$ 


\section{Introdução}

Em 2019, a indústria de games - incluindo devices e jogos para PC, consoles e mobile, além de mídias interativas (produção de conteúdo em vídeo a respeito de jogos eletrônicos e XR - Extended Reality —, que engloba realidades virtual, aumentada e mista) movimentou US\$121,1 bilhões de dólares (SUPERDATA, 2020). Trata-se da segunda maior indústria de entretenimento em todo o mundo, atrás apenas da televisão. Segundo Scott Hawkins (2020), responsável pelo licenciamento de desenvolvedores para a Nintendo, "a indústria de jogos é maior do que as de cinema e música combinadas". A forma de consumir jogos digitais vem mudando ao longo dos anos e diversificando o mercado. Porém, a capacidade de imersão dos usuários nos jogos sempre foi um ponto de atração.

Conforme Orteza (2018), os efeitos sonoros são parte fundamental no processo de imersão do jogador de videogames. Desde a popularização dos jogos eletrônicos, na década de 1970, com as máquinas de arcade, buscou-se possibilitar a imersão do jogador em um universo fictício no qual ele ainda fosse o protagonista da história. Diferentemente de outras produções audiovisuais, como o cinema, a TV e o teatro, nas quais o usuário é tratado apenas como expectador, nos videogames a postura passa a ser ativa.

Para garantir que o jogador sinta-se ainda mais imerso no universo do videogame, a construção sonora foi, e ainda é, parte imprescindível da criação de um jogo eletrônico. As trilhas sonoras - tanto músicas quanto efeitos (ALVES, 2012) - dos jogos evoluíram de acordo com a melhoria da capacidade técnica dos hardwares, principalmente dos consoles domésticos. O aumento da capacidade de processamento e memória das máquinas permitiu que se alcançassem, nos jogos atuais, efeitos sonoros bastante realísticos (WOLF 2008; GAL et al. 2002). Tais elementos sonoros auxiliam na experiência do usuário, criando não só um processo de imersão (COLLINS, 2008), mas também desempenhando um papel imprescindível nas preferências do consumidor (BUSH et al. 2007).

De acordo com Norman (2008, p. 156), "o desenho de animação e a sonoplastia estão ficando tão bons que games com uso de simulador podem usados para treinamentos de verdade, quer seja pilotar um avião, operar uma estrada de ferro ou dirigir um carro de corrida ou um automóvel". No entanto, nos anos de hardware mais limitado, como os da chamada segunda geração dos consoles (Fairchild Channel F, Atari 2600, Magnavox Odyssey) ou da terceira geração, a "era dos 8-bits" (Famicom/NES, Master System, Atari 7800), o uso de elementos sonoros precisava ser simplificado ao máximo, de maneira a não tornar a experiência sonora do jogo grotesca e, ao mesmo tempo, imprimir um mínimo de realismo às ações dos personagens.

Diante desse cenário, este trabalho buscou avaliar a capacidade do usuário de identificar ações do jogo apenas por seus respectivos efeitos sonoros, com o objetivo de estudar o papel do sound design na experiência do usuário. Para isso, optou-se pelo estudo de caso da interface sonora do jogo Super Mario Bros., lançado pela Nintendo para NES em 1985 e que deu origem a uma das franquias mais importantes de games.

A escolha de um jogo da era de 8-bits justifica-se pelo desafio proposto aos usuários, acostumados atualmente com trilhas de melhor qualidade e definição, para a análise. Além disso, a construção sonora do Super Mario Bros. é considerada uma das mais icônicas da história dos videogames domésticos (GREENING, 2014).

\section{Videogames: um breve histórico}

Os videogames, videojogos ou telejogos surgiram há, aproximadamente, 50 anos e, desde então, estão se consolidando cada vez mais no mercado, na cultura popular e no ambiente de multimídia interativa (LUZ, 2010). Na minissérie documental "GDLK: High Score" (2020a), Howard Scott Warshaw, programador de vários jogos clássicos de Atari, diz que há muitas maneiras de se definir o que é o videogame, mas que,

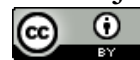


possivelmente, seu maior impacto tenha sido transformar o ato de "assistir à televisão" de algo passivo para ativo.

Os videojogos foram uma das primeiras mídias que permitia que o telespectador se envolvesse ativamente. O videojogo foi a primeira mídia interativa a possibilitar o jogo em um espaço diegético, nos quais sons possuem origens próximas da tela ou nela mesma (LUZ, 2010). McMahan afirma que "os jogadores percebem que videogames não apenas como uma fonte de companheirismo, mas possivelmente como um substituto para ela" (MCMAHAN, 2003, p. 67, tradução nossa) ${ }^{1}$.

Para os usuários, os primeiros jogos eletrônicos pareciam algo mágico (GDLK, 2020a). Em 1978, foi lançado pela Taito Corporation um dos jogos digitais mais icônicos da história, o Space Invaders (Figura 1). Ele foi criado por Tomohiro Nishikado, no Japão, inicialmente para a plataforma arcade (fliperama). Na época, o sucesso foi tamanho que os locais com máquinas de fliperama ganharam o apelido "Invader Houses" em alusão ao jogo (GDLK, 2020a).
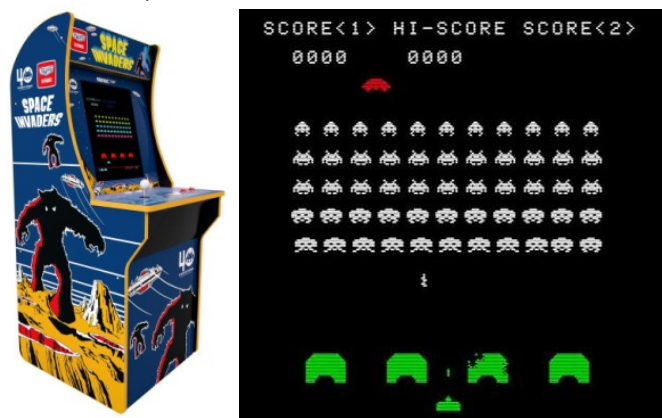

Figura 1: Space Invaders Arcade e Tela do Space Invaders. Fonte: Manor Online Shop e e TechTudo ${ }^{3}$.

Outro passo importante na evolução dos jogos digitais foi a criação dos chamados consoles domésticos, em 1972. Os games saíram dos fliperamas e chegaram às residências com os consoles de primeira geração, como Pong, Coleco Telstar e o primeiro Magnavox Odyssey. A segunda onda, com consoles que aceitavam cartuchos de jogos, teve início em 1976, com o Fairchild Channel F e o Magnavox Odyssey/Videopac, além do Atari 2600 - seu representante mais icônico. A inovação dos cartuchos, segundo Wolf (2008, p. 56, tradução nossa) $)^{4}$, "deu aos consumidores a habilidade de atualizar seus console sem comprar um novo". Apesar de tal inovação não ter transformado o Fairchild em um sucesso, ainda assim ditou uma nova tendência que viria a ser seguida.

O Atari 2600 explodiu em vendas nos EUA (GDLK, 2020a) no início dos anos 1980. Sua ascensão foi acompanhada pelo aumento da quantidade de jogos de baixa qualidade ou "cópias" de outros games de sucesso já estabelecidos anteriormente. Com isso, segundo McLeran (2008, p. 2, tradução nossa) "consumidores americanos rapidamente perderam o interesse nos videogames e a indústria de jogos praticamente entrou em colapso em 1984". Foi o chamado "crash dos videogames". Além disso, o formato dos jogos digitais era limitado e a repetição de fórmulas começou a cansar os usuários (GDLK, 2020a). Conforme aponta Norman (2008, p.130), "o que é divertido num primeiro momento pode desgastar-se mais adiante". Não havia mais desafio.

\footnotetext{
1 they [players] perceive the video games as not only a source of companionship, but possibly as a substitute for it.

2 Disponível em: <https://www.manor.ch/de/p/p2-37496901>. Acesso em: 6 de set. 2020.

3 Disponível em: <https://www.techtudo.com.br/listas/noticia/2016/03/space-invaders-veja-lista-com-curiosidades-e-polemicas-do-jogo.html>. Acesso em: 6 de set. 2020.

${ }^{4}$ Consumers the ability to upgrade their console without buying a new console.

5 [...] American consumers quickly grew disinterested in video games and the game industry virtually collapsed by 1984 . 
Os consoles domésticos voltaram a se popularizar apenas com o surgimento da chamada "terceira geração" ou "era dos 8-bits". A retomada foi capitaneada pelo lançamento do Famicom (Family Computer Disk System) pela Nintendo, primeiro no Japão, em 1983, e depois nos EUA, em 1985. Para buscar novamente o interesse do consumidor, a Nintendo a executou diversas estratégias a fim de adentrar o mercado norteamericano. A companhia renomeou o console para NES (Nintendo Entertainment System) (Figura 2), modernizou suas linhas e buscou se afastar do título de "videogame", criando um conceito novo de produto (BENVENUTTI; BARBOSA, 2010).

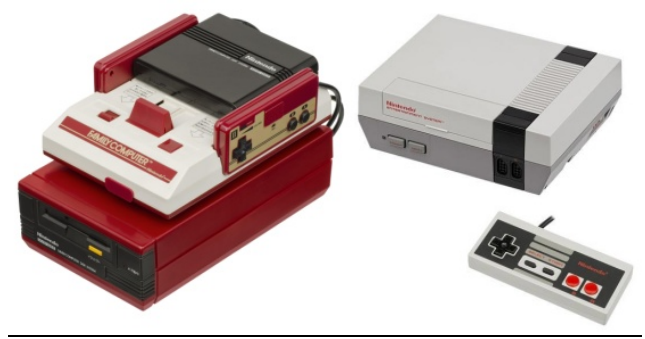

Figura 2: Family Computer Disk System (Nintendo, 1983) e Nintendo Entertainment System (Nintendo, 1985), respectivamente. Fontes: Wikipedia ${ }^{6}$ e eStarland Online Shop ${ }^{7}$.

Após passar por outras gerações disruptivas de consoles e jogos, como a de 16-bits (Mega Drive, Super NES, Neo Geo) e a de 32-Bits (Playstation, Nintendo 64, Sega Saturn), atualmente os videogames estão além do conceito de apenas um brinquedo ou objeto supérfluo: podem ser poderosas ferramentas de entretenimento, comunicação e ensino, dentre outros, e desde a década de 1980 se tornaram focos de estudos acadêmicos por passarem a ser enxergados como mídia (LUZ, 2010). Para Norman (2008, p. 156), os videogames são "uma mistura de ficção interativa com entretenimento". Porém, podem se tornar muito mais do que isso, evoluindo no século XXI para formas radicalmente diferentes de entretenimento, esporte, treinamento e educação. Conforme o autor, inclusive, "o artificial pode deixar de ser distinguível do real" (NORMAN, 2008, p. 159).

Essa notoriedade tanto acadêmica quanto mercadológica do segmento de games começou a ganhar corpo com a criação de um personagem relevante para a história dos jogos. Conforme Loguidice e Barton (2009, p. 192, tradução nossa) ${ }^{8}$, o surgimento do Pac-Man, da Namco, em 1981 (Figura 3), foi um marco por conta do seu sucesso e iconicidade: "Pac-Man eventualmente encontrou seu caminho para lancheiras, cereais matinais, cartoons de sábado de manhã, uma canção famosa e praticamente todo o resto no qual seu rosto poderia ser afixado e vendido numa loja". Como observado em Luz (2010), era a primeira vez que se observava um personagem de jogo eletrônico com carisma suficiente para extrapolar seu meio de origem e protagonizar produtos licenciados.

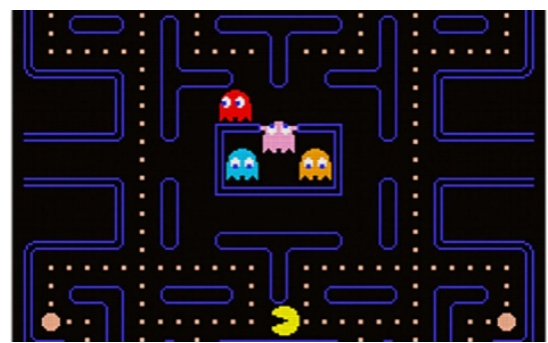

Figura 3: Pac-Man. Fonte: Segredos do Mundo9

\footnotetext{
${ }^{6}$ Disponível em: $<$ https://pt.wikipedia.org/wiki/Family_Computer_Disk_System>. Acesso em: 6 de set. 2020.

${ }^{7}$ Disponível em: $<$ https://www.estarland.com/product-description/NintendoNES/Nintendo-Entertainment-System-NES-Original-Model-RefurbishedSystem---Grade-A/57166>. Acesso em: 6 de set. 2020.

8 PacMan eventually found his way onto lunchboxes, breakfast cereal, Saturday morning cartoons, a hit song, toys, and pretty much anything else that could be affixed with his image and sold in a store.

9 Disponível em: <https://segredosdomundo.r7.com/pac-man-historia/>. Acesso em: 6 de set. 2020. 
Após o Pacman, vários personagens protagonizaram as chamadas franquias de videogames, gerando inúmeros jogos nos mais diversos formatos, sempre aproveitando as personalidades que se tornavam a "cara" das fabricantes. Donkey Kong, Mario, Sonic e Link (da franquia The Legend of Zelda) são exemplos de personagens que transpuseram o tempo e seguiram a evolução tecnológica dos consoles até o momento atual.

Os videogames, portanto, saíram de simples jogos casuais e se tornaram um imenso mercado de entretenimento (YOUNG; MARCHEGIANI, 2005). Aproveitando-se ainda de seu caráter híbrido e interdisciplinar, Ribeiro (2012) analisa que, na construção dos videogames contemporâneos, incorporam-se as mais diversas áreas do design e da arte, por meio da concepção das mecânicas de funcionamento, estruturas físicas das fases, a interface e os estímulos dos sentidos por meio da visão e da audição.

\section{Por que jogamos?}

Diversão e prazer não são tópicos frequentemente abordados pela ciência (NORMAN, 2008). Exemplificando como as emoções influenciam os jogadores, é mais fácil escolher opções com fortes estímulos emocionais e os jogos também se utilizam do afeto para, por exemplo, adicionar conflito (LAZZARO, 2008). Portanto, experiências como diversão e desafio são objetos de consumo dos jogadores.

O ser humano, muita vezes, consome um produto não apenas por sua função ou por sua estética, mas também pela experiência que ele pode lhe propiciar. Para Norman (2008, p. 127), "beleza, diversão e prazer trabalham juntos para produzir alegria, um estado de afeto positivo. [...] As emoções positivas [...] são essenciais para a curiosidade das pessoas e sua capacidade de aprender".

O brincar é inerente ao ser humano e aos demais animais, não só por sua ludicidade, mas também por ser uma importante forma de se adquirir e treinar habilidades. Faz parte do desenvolvimento cognitivo, motor, emocional e social de várias espécies. Conforme aponta Norman (2008), jogos apresentam-se de maneira mais sistematizada do que brincadeiras, geralmente com alguma meta a ser batida e um mecanismo de marcação de pontos. Naturalmente, isso os leva a ser mais competitivos do que o simples brincar, com vencedores e perdedores.

De acordo com Lazzaro (2008, p.154, tradução nossa) $)^{10}$, "mais emocionais do que software e mais interativos do que filmes, os jogos manipulam o sentimento do jogador para criar experiências comoventes". Quando se projeta levando em conta as responsabilidades emocionais, é importante considerar não apenas a estética, mas também a experiência do usuário na sua interação com o produto. Dentro dessas considerações, pode-se afirmar que os videogames são um dos produtos pioneiros em tratar a interação visando as emoções que causam em seus usuários.

A emoção é um fator essencial para manter o usuário focado no jogo: tomar decisões, vivenciar e desenvolver um progresso no jogo precisam ser ricos em emoção e entretenimento para que se prenda a atenção do usuário (LAZZARO, 2008). Uma pesquisa feita com aproximadamente 4.000 norte-americanos sobre seus hábitos de jogo (ENTERTAINMENT SOFTWARE ASSOCIATION, 2020) revelou que a maioria dos jogadores (cerca de 80\%) considera que os videogames os estimula mentalmente. Além disso, $79 \%$ dos respondentes afirmam que relaxam e desopilam enquanto jogam e $65 \%$ dizem que jogar os ajudam se conectar com outras pessoas online ou consigo mesmo.

Tudo que compõe o jogo é passível de construir e influenciar a experiência do jogador. De acordo com Marsh e Costello (2012), o termo "experiência do jogador" enquadra a experiência que os jogadores

10 [...] More emotional than software and more interactive than films, games manipulate player affect to create poignant experiences. 
possuem ao jogar. Um dos aspectos que cria uma boa experiência para o jogador, quando se visam os jogos eletrônicos, é a diversão. Como afirmam Salen e Zimmerman (2004, p. 56), "bons jogos são divertidos. Jogos divertidos são o que os jogadores querem". Sendo assim, a diversão é uma característica fundamental para se projetar jogos bem aceitos.

Mas os games precisam ir além da diversão. Hunicke, LeBlanc e Zubek (2004) afirmam que projetar jogos direcionados às respostas emocionais desejáveis, não limitando-se apenas ao divertimento, parece mais adequado quando se busca por uma experiência mais rebuscada dentro de um jogo. Nesse cenário, é possível identificar a importância da experiência como uma motivação para o jogo ser consumido pelos indivíduos.

\section{Envolvendo o jogador: a experiência de usuário}

A evolução dos meios tecnológicos e o aumento da necessidade da interação entre o ser humano e o computador tornaram o desenvolvimento de interfaces mais relevante, com foco em privilegiar entendimento e manuseio descomplicados (BARBOSA, 2010). Interface, conforme Dul e Weerdmeester (2012), é uma espécie de fronteira entre o homem e a máquina. Para desenvolver interfaces adequadas do ponto de vista ergonômico, é necessário enfrentar diversos obstáculos, como o fato de serem sistemas abertos para os usuários enquanto agentes ativos (CYBIS et. al., 2010).

Para um estudo adequado de interfaces, buscam-se na Interação Humano Computador (IHC) os aspectos que permeiam a comunicação e a relação entre pessoas e computadores. A IHC é uma das áreas de maior relevância quando se leva em conta o estudo da usabilidade e a experiência de usuário (UX) (BARBOSA, 2010). Conforme Iida (2005, p. 320), "usabilidade significa facilidade e comodidade no uso dos produtos, tanto no ambiente doméstico corno no profissional. Os produtos devem ser 'amigáveis', fáceis de entender, fáceis de operar e pouco sensíveis a erros". Já UX é a qualidade do sistema levando em conta os sentimentos e emoções que os usuários possuem em relação a um sistema (BARBOSA, 2010).

Segundo Magain e Chambers (2014, p. 13, tradução nossa) ${ }^{11}$, "experiência do usuário é o quê, onde, quando, por quê, e como alguém usa um produto, bem como quem essa pessoa é". Para Hartson e Pyla (2012), a usabilidade continua importante, mas a experiência do usuário atualmente é ainda mais. Conforme os autores, "embora a usabilidade seja essencial para tornar a tecnologia transparente, nestes dias de extrema competição entre diferentes produtos e maior conscientização do consumidor, isso não é suficiente" (HARTSON; PYLA, 2012, p.13, tradução nossa) ${ }^{12}$.

Marsh e Costello (2012) afirmam que a usabilidade é diretamente relacionada com a experiência do usuário, já que, com a disseminação de sistemas computacionais, a qualidade desses sistemas torna-se cada vez mais importante para que o produto seja mais ou menos aceito dentre os usuários. No entanto, conforme apontam Hartson e Pyla, (2012), experiência do usuário não pode ser projetada, e sim vivenciada. É possível relacionar à UX tudo que é passível de ser vivido - comércio, lazer, entretenimento, etc. - abarcando desde emoções e aspectos psicológicos até fatores físicos que um produto ou serviço proporciona aos usuários (MARSH; COSTELLO, 2012).

Quando se trata de UX no contexto dos jogos eletrônicos, não há um consenso sobre como defini-la. Hodent $(2018 \text {, p. 106, tradução nossa })^{13}$ considera "toda a experiência do jogador com o jogo - dos menus

\footnotetext{
11 User experience is the what, where, when, why, and how someone uses a product, as well as who that person is.

12 While usability is essential to making technology transparent, in these days of extreme competition among different products and greater consumer awareness, that is not sufficient.

13 My practical approach to game UX is to consider the whole experience players have with the game itself-from interacting with menus to the [...] visual and audio aesthetics, as well as how they engage cognitively and emotionally with the game, their motivation to keep playing, and how players remember their experience afterward. 
interativos [...] à estética visual e sonora, assim como o engajamento cognitivo e emocional com o jogo, a motivação que o leva a continuar jogando e como ele relembra o jogo após o fim da experiência".

De acordo com Barbosa (2010), tanto a usabilidade quanto a experiência de usuário são influenciadas pela cognição do usuário e sua capacidade de agir dentro da interface, além do potencial de compreender as respostas do sistema. Conforme apontado por Iida (2005), o usuário constrói um modelo mental que corresponde a uma representação da estrutura e do funcionamento de um sistema durante a interação. Sendo uma mídia ativa que extrapola o conceito do jogador como usuário passivo (MARSH; COSTELLO, 2012), o videogame é um sistema bastante complexo que envolve, para uma completa experiência do jogador, elementos gráficos e sonoros.

\subsection{A experiência além das telas: o sound design em jogos}

Com a popularização desenfreada dos videogames como bens de consumo, veio a necessidade de agradar e envolver um público cada vez mais exigente. Importava corresponder e inovar, mesmo com as limitações técnicas existentes. O som foi um dos elementos revolucionários nos jogos e passou a ser um ponto de interesse para auxiliar no processo de imersão dos jogadores, bem como para demonstrar avanço (FOX, 2016).

Cunningham, Grout, Picking (2011) ressaltam que é preciso considerar, do ponto de vista dos usuários, até que ponto o som é percebido como importante, dado que a indústria de games colocou um foco maior no uso de som e música nos jogos - como se percebe pela mudança dos bipes e cliques de jogos como Space Invaders para alternativas modernas, como a franquia Guitar Hero.

Os sons são elementos relevantes para o aprimoramento do jogo como experiência. Calvillo-Gámez, Cairns e Cox (2015) propõem uma técnica para avaliar UX em games. O questionário CEGE (Core Elements of the Gaming Experience ou Elementos Básicos da Experiência de Jogo, tradução nossa) foi desenvolvido pelos pesquisadores para mensurar as variáveis observáveis da experiência de jogo. As recomendações englobam, ao todo, 38 diretrizes. Três delas envolvem sound design, o que reforça a importância dos elementos sonoros para a experiência do usuário: "27. Os efeitos sonoros do jogo eram adequados", "30. Os gráficos e os sons do jogo são coerentes" e "31. O som do jogo afetou a maneira como eu estava jogando" (CALVILLOGÁMEZ; CAIRNS; COX, 2015, p. 60, tradução nossa) ${ }^{14}$.

Em meio ao avanço constante dos consoles, é possível traçar paralelos quanto ao sound design em jogos e em outras mídias como o cinema e a TV. É possível também diferenciá-los. Conforme Nguyen (2019, p. 1, tradução nossa) $)^{15}$, o principal ponto de contraste entre sons em jogos e filmes é a definição de jogos como "interativos, o que torna difícil o design de sons devido à imprevisibilidade". Assim, a produção de áudio para jogos pode ser descrita como um "desafio" pela necessidade de prever diversos cenários distintos, mediante a incógnita em relação às atitudes/ações dos usuários no jogo. É válido ressaltar que, dentre os representantes marcantes da "era 8-bits", o Super Mario Bros. destacou-se de forma icônica por ser "o primeiro jogo a empregar música verdadeiramente interativa" (MCLERAN, 2008, p. 3, tradução nossa) ${ }^{16}$.

Mantendo em foco a complexidade da elaboração do áudio para jogos por serem meios interativos, Nguyen (2019) propõe em seu trabalho um modelo para tipificar as diferentes formas de som presentes em um jogo. Podem-se categorizar os sons dentro de duas categorias principais: diegéticos (com origens visíveis) e nãodiegéticos (fora do cenário como um todo). Já Ekman (2014) trabalha o conceito da diegese dentro do sound

\footnotetext{
14 27. The sound effects of the game were appropriate. [...] 30. The graphics and sound effects of the game were related. 31 . The sound of the game affected the way I was playing.

15 Interactive which makes it difficult to design sounds because of the unpredictableness.

16 Super Mario Bros. was the first game to employ truly interactive music. 
design para jogos de forma distinta, dividindo-o entre os termos diegéticos (algo "real" dentro do mundo do jogo) e não diegéticos (algo que não faz parte do mundo do jogo). $O$ autor sugere a elaboração de um modelo de estrutura que mescla conceitos de signo e referentes semióticos com os conceitos de diegese já citados para interpretar e expandir as classificações dos sons em um jogo.

Os sons diegéticos podem ainda ser categorizados em três tipos de áudio: interativo, que remete aos sons correspondentes às ações do jogador com objetos; adaptativo, que independe do jogador em si; e dinâmico, que pode se encontrar entre as duas variações citadas anteriormente. Além disso, observam-se certos sons que pertencem a um espectro sonoro maior, dentro de três camadas de efeitos sonoros: de ambientação de fundo (sons do ambiente, com duração variável e projetados para criar certa distinção ou identidade para o jogo); sons de primeiro plano (que se relacionam com as ações e interações do jogador com objetos localizados no plano visível da tela); e sons de interface (relacionados com ações referentes a interações com menus e opções do jogo) (NGUYEN, 2019).

Fox (2019) destaca parte dos desafios das funções de um sound designer ao ressaltar em seu trabalho a grande importância de Koji Kondo como responsável pela composição das trilhas musicais de Super Mario Bros.. O autor cita que "Kondo utiliza música para criar várias funções que operam em par com as imagens em movimento [...] a música também trabalha com a gameplay para manter a imersão do jogador para que continue a jogar" (FOX, 2016, p. 2, tradução nossa) ${ }^{17}$.

Em meio a grande variedade de possíveis abordagens e conceitos para induzir a imersão do jogador e, ao mesmo tempo, criar uma identidade para o jogo por meio do som, é importante também destacar o desafio encontrado por sound designers ao lidarem com questões como limitações técnicas em consoles de 8-bits durante os anos 1980. Segundo Gal et.al (2002, p. 5, tradução nossa) $)^{18}$, "nesses casos $o$ sound design é restringido pela falta de armazenamento e poder de processamento" e, assim, o trabalho do designer baseavase na utilização de uma quantidade limitada de notas pré-gravadas, com baixa amostragem e de pouca qualidade.

\subsection{Jogos de 8-bits e o desafio dos sound designers}

Entre o final dos anos 1970 e o início dos anos 1980, os consoles vigentes (e.g. Atari 2600, Magnavox Odyssey) tinham uma capacidade sonora limitada. Apesar de contarem com um seletor de 4-bits em cada um de seus dois canais, seus chips de processamento tinham a capacidade de externalizar entre 4 e 5-bits (FARQUHAR, 2018), tornando restritas as possibilidades de construção sonora.

O Famicom/NES destacou-se como o primeiro console com saída de áudio real de 8-bits (KENT, 2001). Os primeiros jogos com som propriamente dito utilizaram hardware dedicado - como o chip 2A03, do Famicom/NES. Além disso, conforme visto em Benvenutti e Barbosa (2010), desenvolvedores da Nintendo buscavam meios de estender a capacidade do console, como chips instalados em alguns cartuchos. Segundo os autores, "todo o áudio reproduzido pelo console de 8 bits da Nintendo tem sua origem em quatro fontes distintas: a unidade de áudio do console, os processadores de áudio externos (localizados em alguns cartuchos), o sistema de disquetes e o microfone do segundo controle (joystick) do Famicom” (p. 2).

A maior parte do processamento era feita na CPU (unidade de processamento central) do NES, uma versão modificada de um microprocessador de 8-bits produzido pela MOS Technology (EUA), aprimorado por um chip APU (unidade de processamento acelerada) pela Nintendo para gerar e produzir sons. "A APU do NES contava com cinco canais que trabalhavam sempre em paralelo: as alterações feitas nos parâmetros de um

\footnotetext{
17 Kondo uses music to create various functions that operate in tandem with the moving image [...] the music also works with the gameplay to maintain player immersion so that they will continue to play.

18 In this case the sound design is both constrained by the lack of storage and computing power. 
canal não teriam efeito até que o próximo ciclo interno dela inicie (TAYLOR, 2004b) ${ }^{19}$. Isso deu aos compositores um número muito maior de possibilidades sonoras.

Além disso, o NES também contava com um canal de samples, o que permitiu ao console executar sons que eram típicos dos arcades e que as trilhas sonoras alcançassem uma maior complexidade. Segundo Collins (2008, p. 9), até então os sons dos jogos tinham usos distintos, como atrair um jogador que passava pelos fliperamas e dublar ações do jogo de forma natural. Com o NES, pela primeira vez conseguiu-se aproximar o mundo da música e o dos videogames.

Contudo, a música e os efeitos sonoros dividiam sua execução entre os canais, obrigando os designers a ponderar e formular uma hierarquia sonora para a execução do jogo - sendo esta não apenas uma questão de programação, mas também de estética e, consequentemente, de imersão do usuário. Embora o NES contasse com cinco canais de áudio independentes, havia certos momentos em que era requisitado que um mesmo canal reproduzisse dois ou mais efeitos sonoros. Portanto, compositor e desenvolvedor determinariam qual som seria reproduzido primeiro (BENVENUTTI E BARBOSA, 2010).

Collins (2008) ressalta que essa hierarquia não pode parar a execução de determinados efeitos de áudio, muito menos a trilha sonora: é fundamental garantir uma continuidade musical ao longo da experiência de jogo. Benvenutti e Barbosa (2010) comentam que o trabalho dos designers de som muitas vezes se misturava ao trabalho de um engenheiro de som, exigindo muito cuidado na construção sonora e considerando as limitações e disponibilidades técnicas do console. Em suma, um trabalho similar à mixagem.

Apesar da evolução em relação aos jogos anteriores, as limitações dos consoles de 8-bits ainda eram bastante grandes. Isso fazia com que os sons fossem dos jogos eletrônicos dessa era fossem muito simples. Tal fato trazia ao sound designer um forte desafio: o de envolver o jogador utilizando sons que mais pareciam "bleeps" e "plóins" do que de sons reais, bem diferente dos jogos atuais.

Conforme afirmam Gal et.al (2002, p. 5) ${ }^{20}$, em 8-bits, "a maior parte do sound design são composições brincando com, no melhor caso, sons engraçados e irritantes e loops musicais arquivados no cartucho". Apesar das limitações, Braguinski (2018) ressalta que a construção sonora dos jogos de 8-bits tornou-se muito mais um símbolo de uma era do que uma representação de um período de subdesenvolvimento tecnológico, visto que sua estrutura hoje é revivida por meio de fenômenos como o retrogaming.

\subsection{O fenômeno do retrogaming}

Até o final da década de 2000, a indústria de games ainda era exclusivamente movida por novas tecnologias. Antigo era sinônimo de ultrapassado. Porém, é possível inferir que, à medida que os primeiros gamers envelheceram, começou uma busca ávida pelos primeiros jogos. O apreço pelo retrô é, portanto, "um fenômeno recente no universo dos videogames" (WULF et al. 2018, p. 1, tradução nossa) ${ }^{21}$.

Após o advento da Internet comercial, o retrogaming conquistou um grande espaço nas comunidades virtuais, estimulando as empresas do meio a introduzirem no mercado seus jogos mais antigos na forma de emulações, compilações, adaptações e relançamentos de games e consoles clássicos. Heineman (2014, p. 14,

\footnotetext{
19 The APU is composed of five channels [...] which are always running in parallel. Modification of a channel's parameter [...] doesn't take effect until that unit's next internal cycle begins.

20 So most of the sound design is a composition playing with, 5 in the best case funny and generally irritating, sound and music loops stored in the cartridge.

${ }^{21}$ Perhaps unsurprisingly then, retro gaming is a recent phenomenon in video game culture - gamers are starting to return to their initial and past experiences with games. 
tradução nossa) $)^{22}$ explica que "na última década, na medida em que o retrogaming popularizou-se e a indústria de jogos definiu quais eram os jogos clássicos, essa subcultura deixou de ser exclusiva das autoridades sobre os jogos antigos", sendo assim incorporada à cultura popular.

Uma possível explicação para o sucesso do retrogaming é o sentimento de nostalgia, um fenômeno psicológico que leva à sensação de bem-estar. De certo modo, o retrogaming permite que os jogadores entrem em uma "máquina do tempo" digital e vivam algum ponto no passado (WULF et al. 2018). Os jogos eletrônicos têm um impacto em como as pessoas se identificam e observam o mundo, "ao jogá-los hoje e comparar com as experiências pessoais da era clássica, o jogador desenvolverá uma consciência entre as similaridades do passado e do presente" (HÖRTNAGL, 2016, p. 46, tradução nossa) ${ }^{23}$.

\section{Estudo de Caso: Super Mario Bros. (Nintendo, 1985)}

Lançado em 1985 para o NES, Super Mario Bros. (Figura 4) é considerado um dos videogames mais icônicos já produzidos. A estreia do personagem aconteceu em 1981, em Donkey Kong, criado pela Nintendo para fliperama. Na época, Mario era chamado de Jumpman. Seu objetivo era salvar uma "donzela em perigo", mantida presa por um gorila gigante - o próprio Donkey Kong. Para cumpri-lo, precisava saltar ou destruir barris lançados pelo gorila, enquanto subia escadas e rampas em direção à donzela. Donkey Kong foi um dos jogos mais cultuados (HOROWITZ, 2020) da era dos fliperamas, sendo uma franquia de bastante sucesso mesmo em videogames mais atuais.

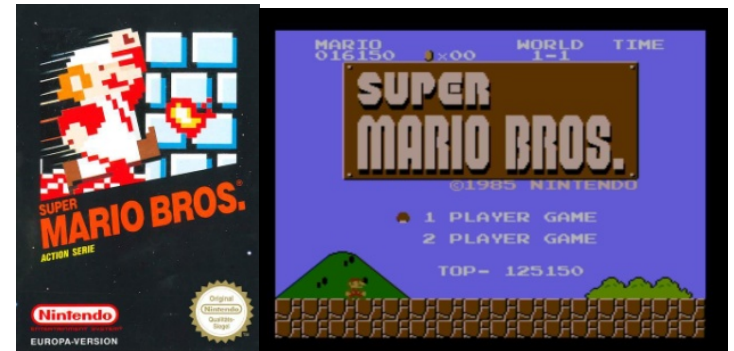

Figura 3: Capa do cartucho e tela do jogo Super Mario Bros, respectivamente. Fonte: Nintendo ${ }^{24}$

Mas foi o seu spin-off quem conquistou de vez os corações dos jogadores. O personagem Mario, um encanador baixinho, bigodudo e muito carismático, inaugurou outra franquia diretamente nos consoles, popularizando os chamados jogos de plataforma (side scrolling games). Seu legado à frente da franquia inclui também games de corridas de kart (Mario Kart), puzzle (Dr. Mario), esportes (Mario Hoops, Mario Golf, Mario Tennis) e diversos outros formatos, como jogos de tabuleiro, RPGs e jogos educativos.

Para a presente pesquisa, a escolha por analisar a relação entre UX e sound design em um jogo da era de 8bits justifica-se pelo desafio proposto aos usuários, acostumados atualmente com trilhas de melhor qualidade e definição. E, dada a importância e iconicidade de Super Mario Bros. (conhecido também por Mario 1), o estudo de caso a partir desse jogo foi uma escolha natural. Além de ter inaugurado uma das franquias de maior sucesso da história dos games, Super Mario Bros. alcançou mais de 40 milhões de vendas, tornando-se possivelmente um dos 10 jogos eletrônicos mais vendidos de todos os tempos (SIRANI, 2019). Não à toa, Mario é até hoje o símbolo máximo de sua fabricante, a Nintendo.

\footnotetext{
22 In the past decade then, as retrogaming became more popular and the gaming industry started defining classic games, [...], retrogaming subculture began to lose its status as the primary authority on older games.

${ }^{23}$ By drawing from their experiences in the emulator and comparing them with their personal memories from the classic era, they develop awareness of similarities and differences between now and then.

${ }^{24}$ Disponível em: <https://www.nintendo.pt/Jogos/NES/Super-Mario-Bros--803853.html>. Acesso em: 6 de set. 2020. 
Os efeitos sonoros utilizados no jogo padecem das limitações técnicas do console NES, que forçaram os compositores a adotarem estratégias que mantivessem uma estética agradável e pudesse garantir um conforto ao jogador, como a repetição do tema de fundo ou a sequência aleatória das faixas (COLLINS, 2008). Apesar disso, observa-se que o padrão sonoro desenvolvido por Koji Kondo para Super Mario Bros. manteve-se basicamente o mesmo em todos os jogos de plataforma subsequentes (COLLINS et. al, 2011), com atualizações na qualidade e na definição dos sons. Assim, considera-se a construção sonora da franquia uma das mais icônicas da história (GREENING, 2014). Ações como pular ou pegar moedas eternizaram-se de forma bastante característica, passíveis de serem reconhecidos por jogadores em qualquer versão do videogame.

\section{Materiais e Métodos}

Buscou-se, neste estudo, compreender se um jogo bastante familiar, como o Super Mario Bros., permitia ao usuário identificar as sonoridades conforme as ações do jogo. Um correto projeto de som pode ser um grande diferencial para a jogabilidade, auxiliando o usuário a perceber, mesmo que de maneira periférica, as ações executadas - além do som servir como uma ferramenta de aprendizado das ações. Optou-se por fazer essa análise com o "Mario 1" por ser um jogo bastante popular e que criou a identidade sonora da franquia. A aplicação do método, porém, pode ser estendida a outras franquias, de maneira a entender como o sound design é importante para que um jogo estabeleça uma relação com o usuário que vá além da interface visual.

Para a coleta de dados para estudo da relação entre UX e sound design no Super Mario Bros., foi elaborado uma avaliação focada nos efeitos sonoros do jogo. O objetivo era analisar se, somente ao ouvir os principais sons do jogo, os usuários seriam capazes de identificar as respectivas ações do personagem Mario. Além disso, buscou-se observar se o nível de frequência com que os respondentes jogavam e seu grau de familiaridade com o game, bem como o conhecimento autodeclarado de outros games da franquia Mario, refletiam de alguma forma na capacidade de identificação dos efeitos sonoros.

Foi elaborado um questionário composto por 15 questões na plataforma Google Forms, sendo as cinco primeiras para delinear o perfil da amostra. O questionário foi disponibilizado na Internet, divulgado pelos pesquisadores via redes sociais (Instagram, Facebook, WhatsApp) e por e-mail, e ficou aberto a respostas entre às $12 \mathrm{~h}$ de 29 de agosto e aproximadamente mesmo horário de $1^{\circ}$ de setembro de 2020 . Optou-se por manter o formulário online por esse período de 72 horas independentemente do número de respondentes. Para participar, o usuário precisava informar o seu e-mail com o objetivo de se limitar uma participação por pessoa (gerar uma amostra sem reposição). Era possível acessar o questionário via computadores e dispositivos móveis (tablets e smartphones). Importante frisar que buscou-se uma amostragem de conveniência, não probabilística.

Ao acessar o link ${ }^{25}$, o participante deveria preencher alguns dados pessoais, informar sua frequência de jogo e nível familiaridade com o videogame Super Mario Bros., sendo essas duas últimas questões respondidas por meio de uma escala Likert de cinco níveis. Foram coletadas informações como idade, gênero e se a pessoa já teve contato com algum outro jogo da franquia além do "Mario 1". A seguir, o respondente era convidado a responder dez questões, nas quais deveria relacionar um som existente, isolado da primeira fase do jogo, com a ação executada pelo personagem Mario. O respondente poderia ouvir o som quantas vezes quisesse e marcar a opção desejada no questionário, podendo retornar caso desejasse mudar alguma resposta. Ao finalizar o questionário, o respondente recebia um "score" com o número de respostas acertadas.

Cada questão sobre a identificação dos efeitos sonoros aparecia em uma tela independente dentro do questionário, de modo a não confundir o participante. O som a ser avaliado podia ser ouvido ao dar "play"

\footnotetext{
25 Disponível em https://forms.gle/VqRfnturttfUBuyi6

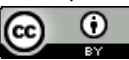


em um vídeo no YouTube, ilustrado apenas pela imagem de capa do cartucho Super Mario Bros. e identificado pelo número da questão (ex.: "Som 1 - Dê play e escute o primeiro som"). As opções de ação eram apresentadas como uma lista, sendo que o participante só poderia escolher uma alternativa (conforme Apêndice). Não havia nenhum outro elemento que pudesse dar pista de qual era aquela ação. Também não havia restrições para se marcar mais de uma vez a mesma alternativa/identificação de ação em perguntas distintas.

As opções dos sons seguiram as tipificações propostas por Nguyen (2019). Foram isolados dez sons característicos da primeira fase do jogo (Tabela 1), que se encaixam nos conceitos de áudio interativo.

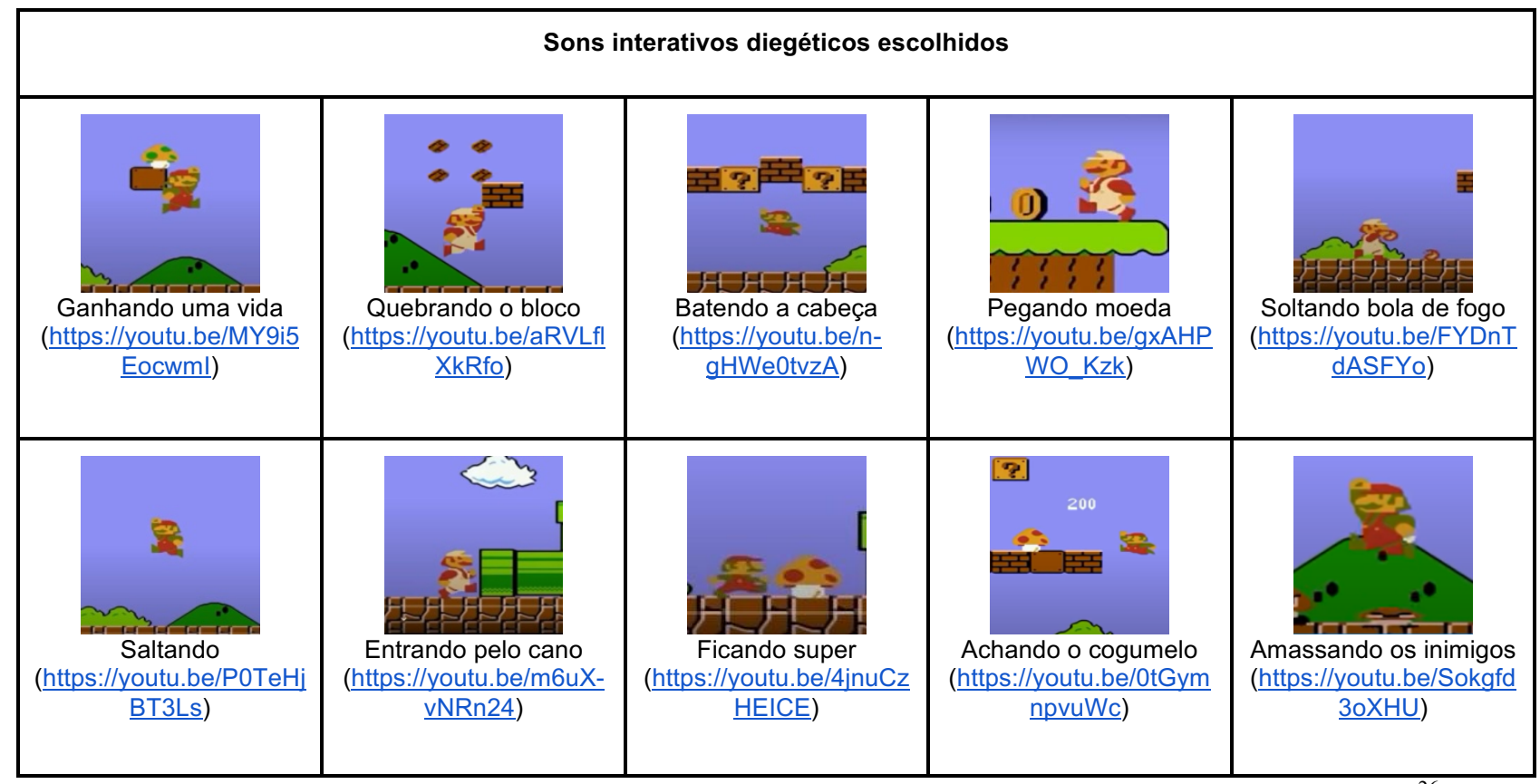

Tabela 1 - Efeitos sonoros do Super Mario Bros. escolhidos para a análise. Fonte das Imagens: Youtube ${ }^{26}$

Importante frisar que o nome das ações foram definidos e adaptados a partir da tradução dos sons isolados, conforme apresentados em The Mushroom Kingdom (2020). Portanto, o som de "power up", quando o Mario adquire um item de poder como o cogumelo, a flor ou a estrela, foi traduzido para "ficando super". Esse termo também foi escolhido pelo fato do primeiro "power up" disponível no jogo ser o cogumelo, que transforma o Mario em Super Mario, fazendo o personagem ficar "grande", ganhar mais velocidade e dar saltos mais altos.

Foram selecionados apenas efeitos sonoros diretamente relacionados às ações do personagem, consequentemente, do jogador. Optou-se por eliminar sons que fazem parte da trilha sonora do jogo (fase completada, morte do personagem, aviso de tempo acabando e outros), sons que poderiam ser redundantes (salto com o Mario pequeno e salto com o Super Mario, que são muito parecidos e poderiam gerar confusão) ou sons obrigatórios/independentes da ação do jogador (como subir no mastro da bandeira para concluir a fase, o que leva a outra trilha sonora).

Objetivou-se, dessa forma, obter um grupo de sons diversificado e representativo do jogo para testar a hipótese de que os efeitos sonoros são uma parte importante da UX em games e, no caso do Super Mario Bros., familiares o suficiente para gerar um alto grau de identificação das ações do personagem apenas por meio da interface auditiva.

${ }^{26}$ Disponível em: <https://www.youtube.com/watch?v=rL19XBg7wSs\&feature=youtu.be>. Acesso em: 6 de set. 2020.

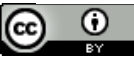


A partir das respostas obtidas, foram elaboradas tabelas de frequência para perfilar a amostra e identificar os resultados. Pela forma de aplicação e divulgação do questionário, a amostra obtida não pode ser considerada representativa em relação à população brasileira quanto ao gênero e distribuição etária. Para analisar as pontuações alcançadas pelos respondentes, foram utilizadas medidas de dispersão (média, mediana e moda) e de variabilidade (variância, desvio padrão - d.p. - e coeficiente de variação - CV), em diferentes recortes da amostra. Também se buscou analisar os respondentes a partir de uma escala de pontuação da relação efeito sonoro-ação, agrupando resultados: pontuações muito baixa (0 a 1), baixa (2 a 4), média (5 a 7$)$ e alta (8 a $10)$.

\subsection{Caracterização da Amostra}

Responderam ao questionário 440 participantes $(\mathrm{N}=440$ ), em uma amostra não probabilística (amostragem por conveniência) quanto aos jogadores do game "Mario 1". Tal amostragem reflete apenas o alcance do questionário, divulgado a partir das redes sociais dos autores deste estudo. Do total, 284 participantes $(64,55 \%)$ se identificaram como do gênero masculino, 147 (33,41\%) como do gênero feminino, $3(0,68 \%)$ como de outro gênero e $6(1,36 \%)$ indivíduos preferiram não informar seu gênero. Quanto à idade, o questionário permitia que o participante escolhesse sua faixa etária. Dentre as possibilidades apresentadas, o maior número de respondentes concentrou-se na faixa entre 20 e 24 anos $(\mathrm{N}=143$, correspondente a 32,5\% do total). A amostra dividiu-se conforme apresentado na tabela 2.

\begin{tabular}{|l|r|c|c|}
\hline \multicolumn{4}{|c|}{ Tabela de frequências - Faixas etárias $(\mathbf{N}=\mathbf{4 4 0})$} \\
\hline Idade & $\mathbf{n i}$ & $\mathbf{f i}$ & $\mathbf{f a c}$ \\
\hline 0 a 9 & 1 & 0,00227 & 0,00227 \\
\hline 10 a 14 & 4 & 0,00909 & 0,01136 \\
\hline 15 a 19 & 40 & 0,09091 & 0,10227 \\
\hline 20 a 24 & 143 & 0,32500 & 0,42727 \\
\hline 25 a 29 & 112 & 0,25455 & 0,68182 \\
\hline 30 a 34 & 59 & 0,13409 & 0,81591 \\
\hline 35 a 39 & 55 & 0,12500 & 0,94091 \\
\hline 40 a 44 & 15 & 0,03409 & 0,97500 \\
\hline 45 a 49 & 7 & 0,01591 & 0,99091 \\
\hline 50 a 54 & 2 & 0,00455 & 0,99545 \\
\hline 55 a 59 & 0 & 0,00000 & 0,99545 \\
\hline acima de 60 & 2 & 0,00455 & 1,00000 \\
\hline Total & 440 & 1,00000 & \\
\hline
\end{tabular}

Tabela 2 - Distribuição da amostra por faixas etárias, sendo ni o número de indivíduos, fi a frequência relativa e fac a frequência acumulada. Em destaque a faixa com maior ni.

Quanto à frequência de jogo, a maioria dos respondentes $(58,18 \%)$ relatou ter jogado bastante (níveis 4 e 5 ) o "Mario 1" (Gráfico 1). Importante salientar que, no questionário, a pergunta estava ilustrada por uma tela da primeira fase do Super Mario Bros., visando facilitar a identificação do jogo pelos participantes: 


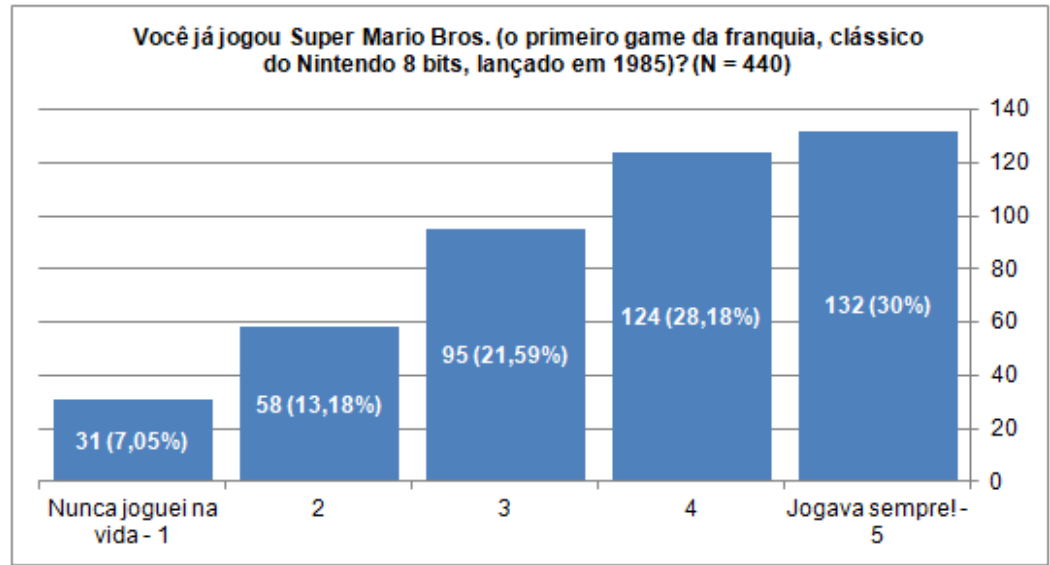

Gráfico 1 - Escala Likert sobre a frequência de jogo com relação a Super Mario Bros.

Já quanto ao nível de familiaridade/conhecimento do jogo autodeclarado, os participantes foram um pouco mais modestos (Gráfico 2), com 41,82\% considerando-se bons conhecedores do game (níveis 4 e 5 ) e com maior número de respostas $(38,64 \%)$ concentrado na faixa intermediária da escala Likert (correspondente a conheço "mais ou menos" o "Mario 1".).

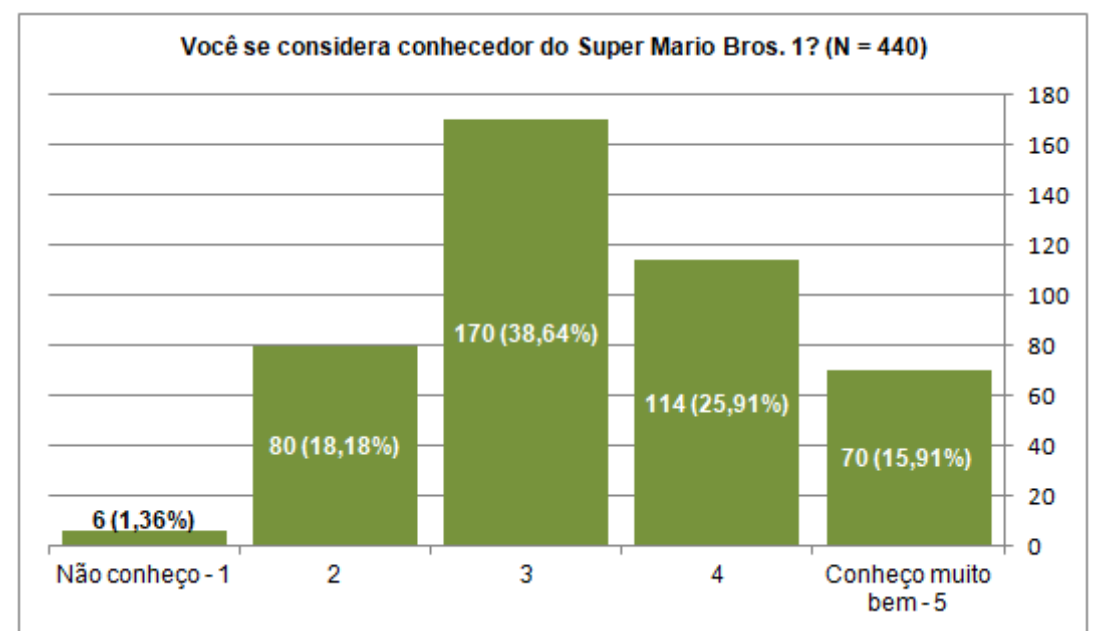

Gráfico 2 - Escala Likert sobre o nível de familiaridade com relação ao jogo Super Mario Bros.

Por fim, impressionantes 398 respondentes (90,45\% do total) declararam já ter jogado alguma outra versão de Super Mario Bros., enquanto 26 (5,91\%) afirmaram não saber e $16(3,64 \%)$ disseram não ter jogado nenhum outro game da franquia.

\section{Resultados e Análise dos Dados}

Com relação à pontuação (acertos da correspondência efeito sonoro-ação) obtida pelos 440 participantes da pesquisa, em um intervalo de 0 a 10, a média foi de 6,18 pontos (d.p. 2,50, CV 0,40), com mediana $6 \mathrm{e}$ moda 8 (Gráfico 3). O coeficiente de variação (CV) é um valor puro, entre 0 e 1, usado para comparar a variabilidade do conjunto de dados. Quando $\mathrm{CV}_{\mathrm{x}}$ está entre 0 e 0,30 , considera-se o conjunto mais homogêneo (pouca variabilidade). Valores de $\mathrm{CV}_{\mathrm{x}}$ acima de 0,70 indicam que o conjunto de dados é mais heterogêneo (muita variabilidade). 


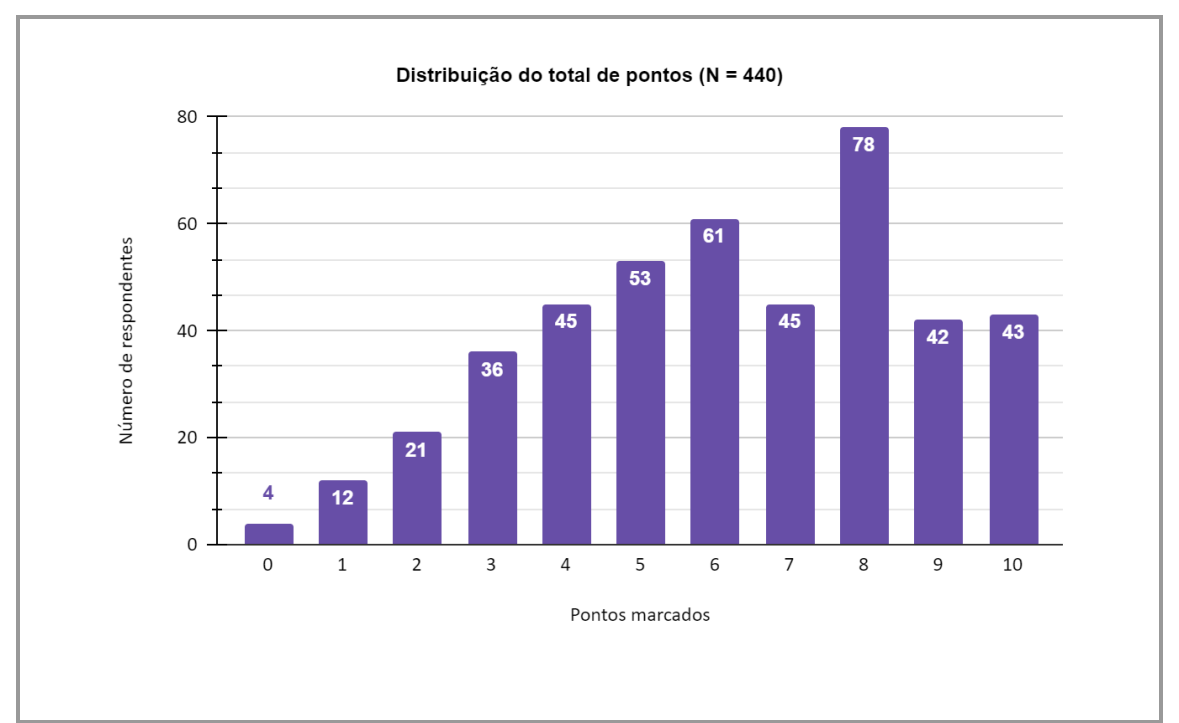

Gráfico 3 - Distribuição do total de pontos (acertos da relação efeito sonoro-ação do jogo Super Mario Bros.), em um intervalo de 0 a 10 , pela amostra geral $(\mathrm{N}=440)$.

Optou-se por analisar as pontuações obtidas nas diferentes faixas etárias em busca de diferenças no desempenho dos respondentes. Para garantir um número de respondentes estatisticamente relevante $(\mathrm{N} \geq 30)$ em cada grupo, agrupou-se os resultados dos participantes até $19 \operatorname{anos}(\mathrm{N}=45)$ e acima de $40 \operatorname{anos}(\mathrm{N}=36)$. De maneira geral, o melhor desempenho concentrou-se na faixa etária entre 20 e 24 anos, que também agrupa o maior número de respondentes (Tabela 3 ).

\begin{tabular}{|c|r|c|c|c|c|c|}
\hline \multicolumn{7}{|c|}{ Tabela de pontuação por faixa etária (N = 440) } \\
\hline Faixa etária & ni & Média & d.p. & CV & Mediana & Moda(s) \\
\hline 0 a 19 & 45 & 5,31 & 2,40 & 0,45 & 5 & 5 \\
\hline 20 a 24 & 143 & 6,73 & 2,34 & 0,35 & 7 & 8 \\
\hline 25 a 29 & 112 & 6 & 2,39 & 0,40 & 6 & 5 e 8 \\
\hline 30 a 34 & 59 & 6,31 & 2,77 & 0,44 & 6 & 8 e 10 \\
\hline 35 a 39 & 55 & 6,07 & 2,46 & 0,41 & 7 & 8 \\
\hline acima de 40 & 36 & 5,50 & 2,89 & 0,53 & 6 & 6 \\
\hline
\end{tabular}

Tabela 3 - Tabela que sumariza resultados de pontuação (acertos da relação efeito sonoro-ação do jogo Super Mario Bros.), por faixa etária, a partir de medidas de dispersão e variabilidade, sendo ni o número de indivíduos, d.p. o desvio padrão e CV o coeficiente de variação. Em destaque a faixa com melhor desempenho.

Outra estratificação analisada foi a pontuação obtida pelos gêneros masculino $(\mathrm{N}=284)$ e feminino $(\mathrm{N}=$ 147) (Gráfico 6). Não se observaram os resultados dos grupos da amostra identificados como outros gêneros $(\mathrm{N}=3)$ e dos respondentes que preferiram não declarar gênero $(\mathrm{N}=6)$ pela ausência de relevância estatística desses grupos de forma isolada. Homens alcançaram pontuações mais altas, com média de 6,8 pontos (d.p. 2,31, CV 0,34), mediana 7 e moda 8, enquanto mulheres obtiveram, em média, 4,94 acertos (d.p. 2,39, CV $0,48)$, com mediana 5 e moda 4. 


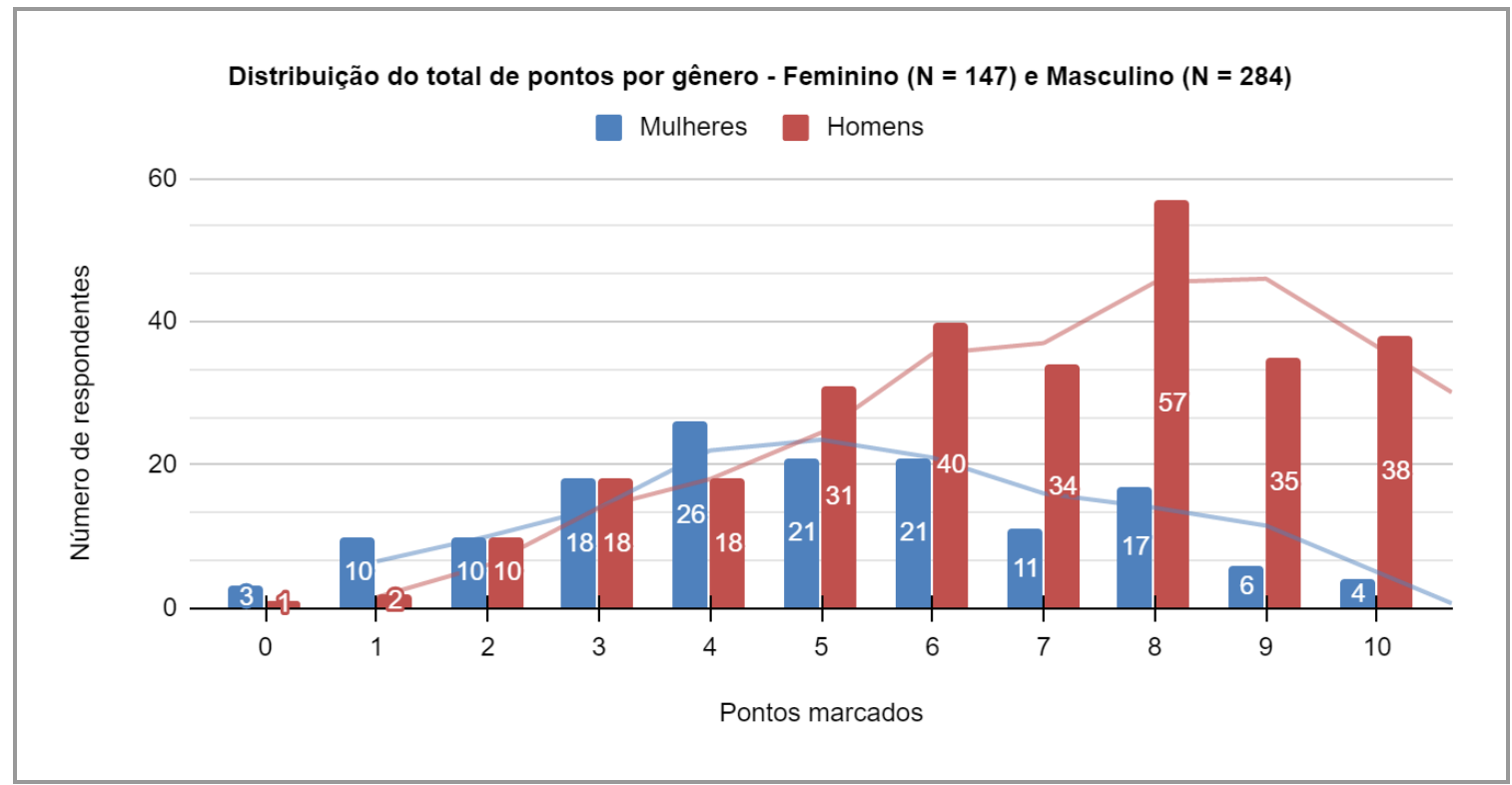

Gráfico 6 - Distribuição do total de pontos (acertos da relação efeito sonoro-ação do jogo Super Mario Bros.), em um intervalo de 0 a 10 , por gênero feminino $(\mathrm{N}=147)$ e masculino $(\mathrm{N}=284)$.

A frequência autodeclarada de jogo não parece ter influenciado o pior desempenho do público feminino. Enquanto 51,70\% das mulheres afirmaram que jogavam "sempre" ou "quase sempre", o percentual dessas resposta subiu para $61,62 \%$ entre os homens. Ainda $23,81 \%$ das mulheres disseram jogar "às vezes" ante $20,77 \%$ dos homens. As respostas "raramente" ou "nunca" para frequência com que jogavam "Mario 1" somam $24,49 \%$ entre as mulheres contra $17,61 \%$ entre os homens.

Porém, pode-se inferir que o pior desempenho alcançado pelas mulheres na correspondência entre efeito sonoro-ação do jogo Super Mario Bros. tenha relação com seu menor nível de familiaridade/conhecimento autodeclarado com relação ao jogo. Apenas 34,69\% do público feminino declarou conhecer "muito bem" ou "bem" o "Mario 1" ante 45,07\% do público masculino. Para 36,73\% das mulheres e 39,44\% dos homens, seu nível de familiaridade do jogo é intermediário. Já as respostas "conheço pouco" e "não conheço" somam $28,57 \%$ entre as mulheres e somente $15,49 \%$ entre os homens.

A partir de uma discussão entre os pesquisadores, definiu-se que pontuações no intervalo entre 0 e 1 seriam consideradas muito baixas, aquelas entre 2 e 4 seriam consideradas baixas, as entre 5 e 7 seriam consideradas médias e, por fim, as pontuações contidas no intervalo entre 8 e 10 seriam consideradas altas. Pode-se observar que $37,05 \%(\mathrm{ni}=163)$ do total de participantes $(\mathrm{N}=440)$ obtiveram uma pontuação alta e $36,14 \%(\mathrm{ni}=159)$ estão na faixa média de pontuação (Gráfico 5), o que revela um alto grau de identificação das ações correspondentes a cada um dos 10 efeitos sonoros do Super Mario Bros. analisados - independentemente da frequência de jogo ou do nível de familiaridade/conhecimento autodeclarados pelos respondentes. 


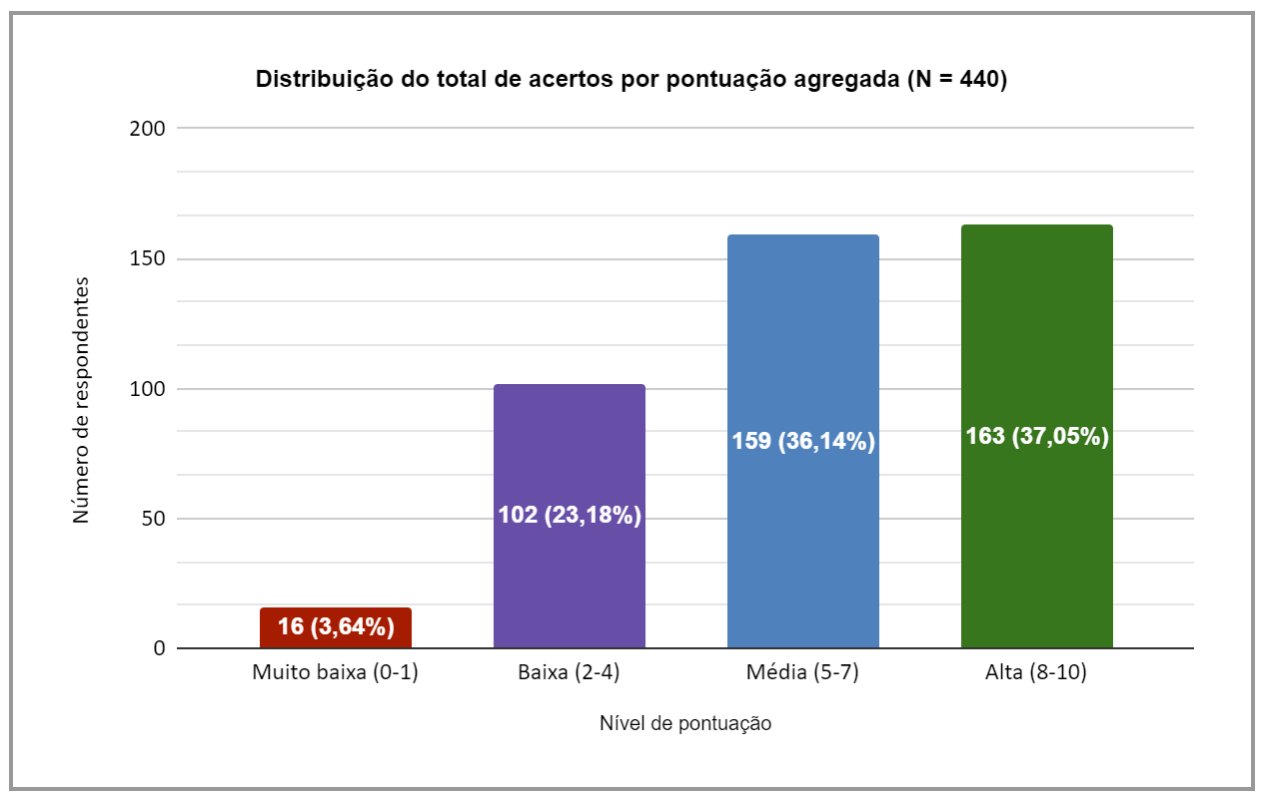

Gráfico 5 - Distribuição do total de acertos (da relação efeito sonoro-ação do jogo Super Mario Bros.), por pontuação agregada, pela amostra geral $(\mathrm{N}=440)$.

Quanto à associação efeito sonoro-ação de jogo pelo total de respondentes $(\mathrm{N}=440)$, cinco sons de ações do personagem Mario tiveram um nível de correspondência correta superior a 70\%: "saltando" (83,41\%) fazendo jus ao primeiro nome do personagem, Jumpman -, "pegando moeda" $(82,50 \%)$, "quebrando um bloco" (75,91\%), "ganhando uma vida" (75\%) e "entrando pelo cano" (74,32\%). Outros dois sons ficaram em patamar intermediário da identificação das ações de jogo: "batendo a cabeça", com 54,55\% de respostas corretas, e "soltando bola de fogo", com 53,18\% de acertos.

Os participantes mostraram dificuldade maior para associar três relações efeito sonoro-ação do Mario, com um grau de identificação correta menor do que 50\%: "amassando os inimigos" (46,36\%), "ficando super" $(39,09 \%)$ e "achando cogumelo" (33,86\%), conforme Gráfico 6.

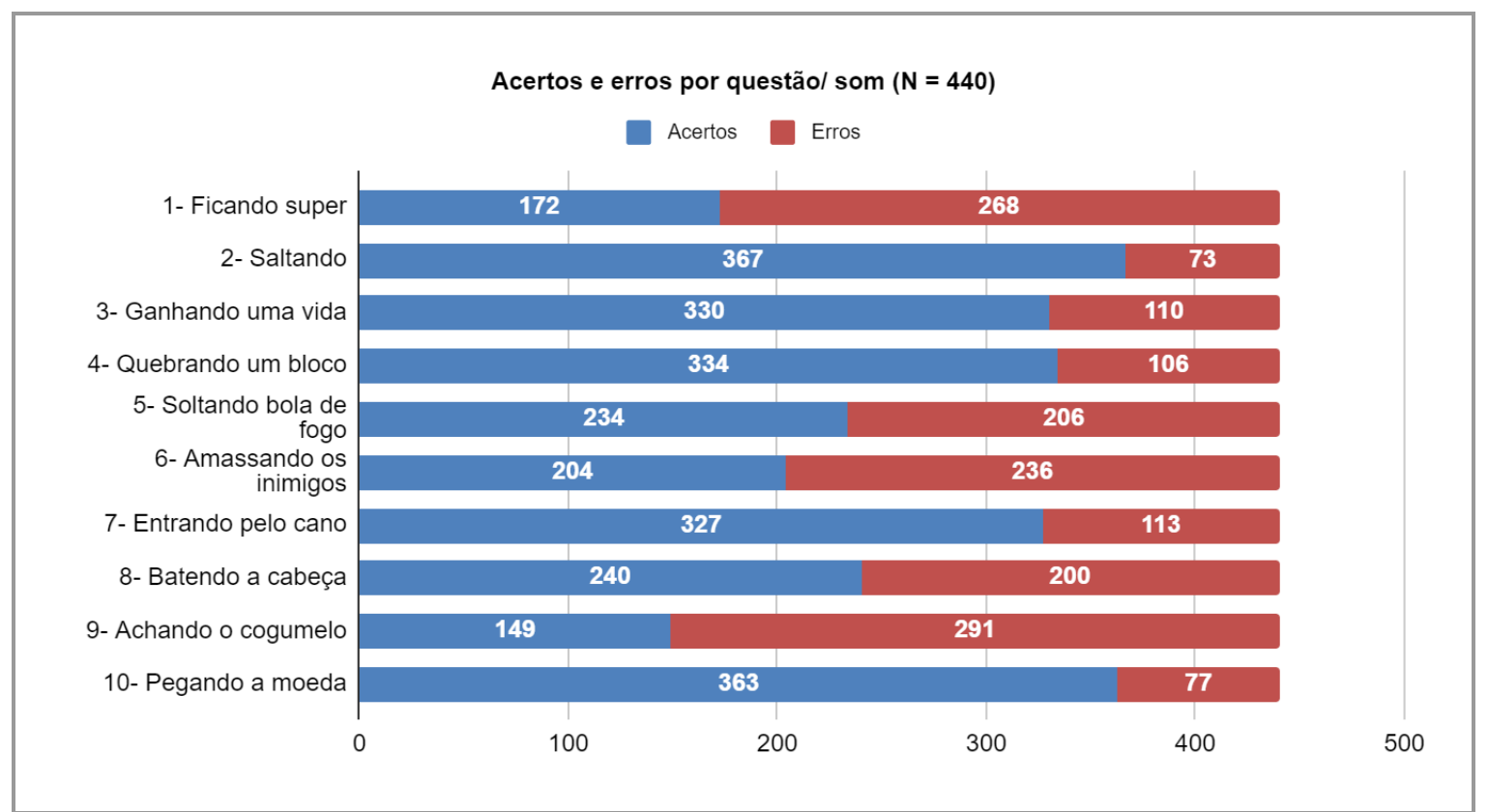

Gráfico 6 - Distribuição do total de acertos e erros (da relação efeito sonoro-ação do jogo Super Mario Bros.), por questão/som, pela amostra geral $(\mathrm{N}=440)$. 


\section{Discussão}

Chama atenção aqui o que pode ser considerado um alto grau de engajamento entre os respondentes do questionário. $\mathrm{O}$ total de 440 respondentes em apenas 72 horas com o formulário aberto indica, provavelmente, o tamanho do interesse pelo assunto pesquisado. Conforme Norman (2008, p. 150), "quando falamos sobre filmes ou outros entretenimentos classificados como 'escapistas', estamos nos referindo à capacidade do estado vicário", no sentido de experimentar algo como espectador como se realmente estivesse participando da história, "e do nível comportamental de afeto de desligar as pessoas dos problemas da vida e transportá-las para outro mundo". Jogar videogame faz parte do momento de diversão das pessoas e a possibilidade de participar de um estudo sobre um assunto tão relevante para parte da população gerou, naturalmente, o chamado "buzz" - espécie de espalhamento do questionário, gerando o alto número de participantes.

Além disso, a pesquisa tinha também um viés na apresentação do questionário que pode ter elevado a um maior engajamento: sua "gamificação". A opção por mostrar o score atingido pelo indivíduo ao final do questionário, além de não gerar frustração por não informar o resultado, também causou um efeito de competição. Foi possível observar nas redes sociais próximas dos autores deste estudo indivíduos comparando a pontuação e discutindo em que acertaram ou erraram. Foram recebidos ainda feedbacks com sugestões para o questionário, agradecimentos pela nostalgia causada, elogios pela proposta de estudo e críticas pelas opções dos nomes das ações. Ficou claro tanto pelo engajamento quanto pelos feedbacks que os sujeitos possuíam familiaridade com o assunto e que a temática tinha apelo emocional.

De acordo com os dados apresentados, pode-se observar uma grande familiaridade não só com o jogo "Mario 1" como também com a franquia Super Mario Bros.. Tal dado, em um primeiro olhar, já responde o porquê de aproximadamente $37 \%$ dos respondentes conseguirem uma pontuação considerada alta (acima de 8). De acordo com Stevens e Raybould (2011, p. 275, tradução nossa $)^{27}$, "sons podem ter conexões fortes com as memórias e por consequência com os sentimentos evocados por essas memórias". Santa Rosa, Pereira Jr. e Lameira (2016, p. 99) explicam que um dos tipos de memória de longa duração implícita (não declarativa) dos seres humanos são as memórias associativas, em que "estabelecemos, previamente, consciente ou inconscientemente, uma associação entre um estímulo e um comportamento". É o que acontece quando os usuários escutam um efeito sonoro e são capazes de associá-lo a uma ação do personagem.

Devido ao alto grau de popularidade da franquia, independentemente da familiaridade com o "Mario 1" e da frequência autodeclarada de jogo, o nível de acertos geral dos respondentes foi alto. Conforme afirma Collins (2011, p. 12, tradução nossa) $)^{28}$, "a franquia Super Mario Bros. [...] tem mantido uma estética distinta através de incontáveis encarnações, plataformas, e avanços tecnológicos" e, mesmo com a limitação causada pelo hardware de 8-bits no questionário aplicado, os efeitos sonoros se mostraram facilmente reconhecíveis pelos participantes. Observou-se ainda que, entre a população geral $(\mathrm{N}=440)$, o maior número de acertos foi no som "saltando" (367 acertos), o que é explicado pelo fato de ser, provavelmente, a ação com efeito sonoro mais constante do personagem.

Sternberg (2000) sugere quatro funções básicas para a atenção humana: atenção seletiva (escolher prestar atenção em algo e ignorar os demais estímulos), vigilância ou detecção de sinal (capacidade de detectar o surgimento de um estímulo de interesse), sondagem (busca ativa por um estímulo) e atenção dividida (recursos de atenção divididos para coordenar o desempenho de tarefas simultâneas). A atividade de

27 Sounds can have strong links to memory and therefore to the feelings evoked by those memories.
28 The Super Mario Bros. series [...] has maintained a distinctive aesthetic through countless incarnations, platforms, and technological improvements
(C) B 
coordenar suas ações, recebendo estímulos visuais e sonoros, pode se encaixar em todas as categorias, a depender do interesse do usuário nos desafios propostos pelo jogo. Para "achar um cogumelo" em Super Mario Bros., por exemplo, é conveniente ativar a função de vigilância da atenção para captar o efeito sonoro correspondente - já que os estímulos visuais tendem a chamar mais a atenção do usuário. A atenção humana permite o uso criterioso dos recursos mentais, pois ambos - atenção e recursos - são limitados e, portanto, é preciso escolher quais estímulos observar e quais devem ser ignorados (SANTA ROSA; PEREIRA JR.; LAMEIRA, 2016).

Relacionar o som à ação executada faz parte do processo de familiarização com os jogos. Conforme afirma Hirokazu Tanaka (GDLK, 2020b), sound designer da Nintendo entre 1980 e 2000, "mesmo que seja só um bip, o som é importante nos jogos. Você precisa do som para confirmar as ações, senão não saberia o que estaria fazendo". Ao ouvir o som nas questões do formulário, imediatamente o participante era levado a imaginar a ação do personagem. Naturalmente, os respondentes que autodeclararam níveis de familiaridade mais altos $(4$ e 5) $(\mathrm{N}=184)$ apresentaram melhores resultados. Desses, 93 respondentes $(21,14 \%$ do total $)$ ficaram na faixa entre 8 e 10 acertos. Fato similar ocorre entre os respondentes que diziam jogar "Mario 1" com maior frequência (entre 4 e $5, \mathrm{~N}=256$ ): 113 respondentes $(25,68 \%)$ ficaram entre os scores altos (entre 8 e 10$)$.

Mesmo entre os que declararam possuir média, pouca ou nenhuma familiaridade com o jogo, uma parcela expressiva apresentou pontuações altas. Considerando o total de 440 respondentes, 70 indivíduos $(15,91 \%)$ que marcaram níveis de familiaridade entre 1 e 3 na escala Likert ficaram na faixa alta de pontuação (8-10). Tal fato pode ser explicado por um viés da pesquisa: independentemente de terem jogado "Mario 1", o contato dos respondentes com outros jogos da franquia permitiu a eles o conhecimento necessário para reconhecer a ação por meio do som. Desses, 67 respondentes afirmaram ter jogado outros jogos da franquia. Curiosamente, os três respondentes que afirmaram nunca ter jogado $(\mathrm{N}=2)$ ou que não sabia $(\mathrm{N}=1)$ já ter jogado outro Super Mario Bros. alcançaram o score 8, o que pode ser explicado pelo fato dos efeitos sonoros do jogo serem bastante icônicos e populares (GREENING, 2014).

Entre os 440 respondentes, ainda é possível observar 50 participantes $(11,36 \%)$ que marcaram ter média, baixa ou nenhuma frequência de jogo (níveis 1, 2 e 3) que obtiveram scores acima de 8 acertos. Porém, na comparação entre gêneros, aparece um grande disparate. Entre os respondentes que se identificaram como do gênero masculino $(\mathrm{N}=284), 130(45,77 \%)$ indivíduos obtiveram scores na faixa alta $(8-10)$, ao passo que, entre os respondentes que se identificaram como gênero feminino $(\mathrm{N}=147)$, a distribuição apontou 54 indivíduos $(36,73 \%)$ na faixa de notas considerada baixa (entre 2 e 4 ).

Nos anos 1980, quando foi lançado o jogo "Mario 1", o desequilíbrio de gêneros entre os jogadores era gritante: $80 \%$ dos jogadores de arcade eram do gênero masculino e $20 \%$ do gênero feminino (KAPLAN, 1983). Ao longo das últimas décadas, houve um crescimento significativo da participação de mulheres no meio gamer. Segundo dados da Pesquisa Game Brasil (2020), 70,5\% dos usuários de jogos mobile são do gênero feminino. Porém, tal predominância ainda não acontece no segmento de consoles domésticos: ainda de acordo com esse estudo, apenas 33,7\% dos jogadores de console são mulheres.

A própria distribuição da amostra da pesquisa apontou uma parcela bem maior de respondentes homens, $o$ que ainda pode indicar maior interesse desse público pelo tema. A menor presença das mulheres entre os jogadores de console e o fator histórico podem ter influenciado na diferença de desempenho entre os gêneros. Ainda que analisar os gêneros possa trazer algumas hipóteses a serem testadas em estudos futuros, ao se observar o estrato por faixas etárias nota-se outro viés. Considerando a maneira como o questionário foi divulgado (redes sociais e e-mail) e a própria faixa etária da maior parte dos autores deste estudo (entre 18 e 23 anos), acredita-se que o alcance do formulário foi maior entre pessoas de 20 a 24 anos devido à proximidade de universos. 
Ao estratificar as faixas etárias, pode-se observar que a maior concentração de resultados altos (entre 8 e 10) apresenta-se entre os respondentes de 30 a 34 anos. Dos 59 indivíduos respondentes, 25 (42,37\%) alcançaram tais notas, sendo que 10 pessoas $(16,95 \%)$ fizeram a pontuação máxima. Conforme observado em GDLK (2020b), pessoas nessa faixa etária praticamente "cresceram com o jogo". Vale ressaltar ainda que, levando em consideração que o público respondente atingido é nascido e vive no Brasil, possivelmente tiveram contato com o "Mario 1" no final dos anos 1980 - diferentemente dos países de lançamento do jogo, Japão e EUA, nos quais Super Mario Bros. estreou no início da década (1983).

Considerando a situação econômica vivenciada no Brasil na primeira metade dos anos 1980 e o fato de as importações legais só terem sido liberadas em 1990 (AVERBUG, 1999), os brasileiros só tinham acesso aos videogames oficialmente lançados no País ou comprando em viagens ao exterior, o que era economicamente inviável para boa parcela da população. Dessa forma, antes de seu lançamento oficial, em 1993, o NES "encarnou" no País por meio de "clones" lançados por marcas nacionais (FERREIRA, 2017), como Gradiente (Phantom System) e Dynacom (Dynavision 2 e 3). Dessa maneira, é possível afirmar que o "Mario 1 " teve seu "boom" no País um pouco mais tarde, o que, provavelmente, faz com que brasileiros nascidos a partir de 1989 sejam os principais "conhecedores" do jogo.

Ainda na questão das idades, curiosamente observa-se na faixa etária seguinte, entre 25 e 29 anos, uma ligeira queda nos resultados. Entre os 112 respondentes, 32,14\% $(\mathrm{N}=36)$ concentraram notas mais altas e $41,07 \%(\mathrm{~N}=46)$ ficaram na faixa de notas médias (entre 5-7). Lançando um olhar para a faixa entre 20 e 24 anos $(\mathrm{N}=143)$, na qual $47,55 \%(\mathrm{~N}=68)$ dos respondentes alcançaram os scores mais altos, pode-se inferir que tal grupo possui um interesse por games maior do que o anterior - o que, possivelmente, os leva a um maior conhecimento sobre retrogames. Importante lembrar que é esta exatamente a geração dos ditos milleniuns. O YouTube surgiu em 2005 e, com ele, a forma de consumir games mudou. Não só se joga hoje, como também se assiste ao jogo alheio. Tanto que o mercado de eSports torna-se cada vez mais promissor. Além disso, essa geração cresceu com novos devices (smartphones e tablets) e, portanto, com mais possibilidades de consumo de jogos.

Ao falar dos sons de um jogo, cabe citar novamente Hirokazu Tanaka (GDLK, 2020b), para quem "o som é necessário em jogos porque eles são inspirados pela vida real. É uma simples imitação da vida".

Possivelmente tal afirmação pode embasar o fato de ações como "saltando", "pegando moeda" e "quebrando o bloco" terem sido as mais acertadas. Mesmo os 56 respondentes (12,73\%) que se autodeclararam como pouco ou nada familiares com o "Mario 1" (níveis 1 e 2) e com frequência baixa ou nenhuma de jogo (níveis 1 e 2) foram capazes de acertar, em sua maioria, as três ações - "saltando" com 40 acertos $(71,43 \%)$, "quebrando o bloco" com 32 (57,14\%) e "pegando moeda" com 45 (80,36\%) - ainda que suas representações sonoras, principalmente com a limitação do hardware 8-bits, sejam bastante minimalistas.

Vale frisar ainda que, especificamente no caso do "saltando", não é possível em um primeiro momento relacionar o som a alguma ação do mundo real. Conforme Norman (2008, p.147), "o som pode ser brincalhão, informativo, divertido e emocionalmente inspirador. Pode encantar e informar. Mas deve ser projetado tão cuidadosamente quanto qualquer outro aspecto do design". Os resultados obtidos ainda mostram como o trabalho do sound designer é relevante para a experiência do jogador, independentemente da similaridade com o real.

Conforme Bible (2018), o sound design pode favorecer uma experiência positiva de jogo de muitas formas mas, principalmente, dando um feedback claro para as ações do usuário, correspondendo às expectativas de som de um jogador. Ao que tudo indica, o sound design do primeiro Super Mario Bros. cumpre bem tais papéis, mostrando-se de fato atemporal e relevante para a UX do jogador. Para Norman (2008), uma das marcas de qualidade do bom design é vencer o teste do tempo. Segundo o autor (p. 131), "o design extraordinário - como literatura, música ou arte extraordinárias - pode ser apreciado mesmo depois de uso contínuo e de presença continuada". 


\section{Considerações finais}

A força do sound design para UX em videogames é bastante evidente. O projeto de trilhas e efeitos sonoros deve ser cuidadosamente pensado para, de fato, permitir o processo de imersão do jogador durante uma partida. Observa-se, a partir do estudo apresentado, que a busca de elementos sonoros que possam auxiliar na ambientação e no reconhecimento das ações dos jogos pode ser tão relevante quanto pensar na interface gráfica, ainda mais quando se compreende que os sons podem levar o usuário a executar melhor os movimentos.

A utilização dos recursos de hardware acaba sendo um diferencial para bons projetos. Ao entender as limitações, como no caso dos antigos consoles de 8-bits, o designer pode, então, elencar as possibilidades de desenvolver padrões e sonoridades minimamente próximas das reais. Identificar os sons faz com que a experiência do usuário torne-se mais positiva, trazendo maior prazer durante um momento de diversão. Atualmente, com consoles bastante poderosos em termos de processamento que permitem o uso de efeitos sonoros ainda mais realistas, cabe ao designer buscar a sonoridade que leve o usuário a mergulhar no universo apresentado no jogo.

Outra questão relevante para o sound design é a busca por assinaturas sonoras atemporais, capazes de criar um padrão de aprendizado que ajude os jogadores a manter um bom desempenho mesmo em diferentes versões dos jogos. Ao analisar a primeira versão da franquia Super Mario Bros., fica evidente que, mesmo para quem não tem familiaridade com o jogo ou para quem tem conhecimento de outras versões, não é difícil identificar as ações por meio da interface sonora. A importância dessa interface pode, inclusive, ser analisada fora do universo dos videogames, buscando correlacionar efeitos sonoros com ações em softwares de uso geral visando uma melhoria da UX, principalmente quando se pensa em públicos com limitações sensoriais como deficientes visuais ou idosos.

\section{Referências Bibliográficas}

ALVES, Bernardo Marquez. Trilha Sonora: o cinema e seus sons. Novos Olhares, São Paulo, v. 1, n. 2, p. 90-95, 30 dez. 2012.

AVERBUG, André. Abertura e integração comercial brasileira na década de 90. In: GIAMBIAGI, Fabio; MOREIRA, Maurício Mesquita (Org.). A economia brasileira nos anos 90. Rio de Janeiro : Banco Nacional de Desenvolvimento Econômico e Social, 1999. p. 43-82.

BARBOSA, Simone. Interação humano-computador. São Paulo: Elsevier, 2010.

BENVENUTTI e BARBOSA. Análise dos Aspectos da Estrutura de Áudio do Console de 8 Bits da Nintendo e as Implicações na Linguagem Sonora. In: IX Simpósio Brasileiro de Jogos e Entretenimento Digital.Trilha de Artes \& Design - Full Papers. 2010. Disponível em: $<$ https://martinbussy.com/analyse-dela-structure-audio-de-la-console-8-bits-de-nintendo-et-des-implications-dans-le-langage-sonore-2011/>. Acesso em: 02 de set. 2020.

BIBLE, Tom. Sound Design and User Experience. In: The Gamer's Brain: how neuroscience and UX can impact video game design. New York: CRC Press, 2018. p. 121-123.

BOOM \& BUST (Temporada 1, ep.1). GDLK: High Score. Direção de William Acks, Sam Lacroix, France Costrel, Melissa Wood. Produção de William Acks, Sam Lacroix, France Costrel, Melissa Wood, Courtney 
Coupe. 2020a. (47 min.), son., color. Legendado. Disponível em:

$<$ https://www.netflix.com/watch/81058575?trackId=200257859>. Acesso em: 3 set. 2020.

BRAGUINSKI, Nikita. The resolution of sound: Understanding retro game audio beyond the '8-bit' horizon. Necsus - European Journal Of Media Studies. Amsterdã, p. 105-121. jul. 2018.

Importance of Audio In Gaming: Investing in Next Generation Sound. Entrevistador: Martin H. Klein. Entrevistados: Tracy W. Bush, Scott Gershin, Adam Boyd, Sarju Shah. [S. L.] GDC Vault, 31 jan. 2013. Podcast. Disponível em: < https://www.gdcvault.com/play/668/The-Importance-of-Audio-In>. Acesso em: 06 set. 2020.

CALVILlO-GÁMEZ, Eduardo H.; CAIRNS, Paul; COX, Anna L. Cox. Assessing the Core Elements of the Gaming Experience. In: BERNHAUPT, Regina. Game User Experience Evaluation. Human-Computer Interaction Series. s.1.: Springer International Publishing Switzerland, 2015. p. 37-62.

COLLINS, Karen. Game Sound: an introduction to the history, theory, and practice of video game music and sound design. Cambridge: Mit Press, 2008. 213 p.

COLLINS, Karen et al. Sound in Electronic Gambling Machines: A Review of the Literature and its Relevance to Game Sound. In: GRIMSHAW, Mark. Game Sound Technology and Player Interaction: Concepts and Developments. Hershey: Information Science Reference (an imprint of IGI Global), 2011. p. $1-21$.

COMEBACK KID (Temporada 1, ep.2). GDLK: High Score. Direção de William Acks, Sam Lacroix, France Costrel, Melissa Wood. Produção de William Acks, Sam Lacroix, France Costrel, Melissa Wood, Courtney Coupe. 2020b. (47 min.), son., color. Legendado. Disponível em:

$<$ https://www.netflix.com/watch/81058575?trackId=200257859>. Acesso em: 3 set. 2020.

CYBIS, Walter; Betiol, Adriana; Faust, Richard. Ergonomia e usabilidade: conhecimentos, métodos e aplicações. 2. ed. São Paulo: Novatec Editora, 2010.

CUNNINGHAM, Stuart; GROUT, Vic; PICKING, Richard. Emotion, Content, and Context in Sound and Music. In: GRIMSHAW, Mark. Game Sound Technology and Player Interaction: Concepts and Developments. Hershey: Information Science Reference (an imprint of IGI Global), 2011. p. 235-263.

DUL, Jan; WEERDMEESTER, Bernard. Ergonomia Prática. 2. ed. [S. L.]: Edgard Blucher, 2004. 152 p.

FERREIRA, Emmanoel. A guerra dos clones: clonagem e pirataria na aurora dos videogames no Brasil. In: XL CONGRESSO BRASILEIRO DE CIÊNCIAS DA COMUNICAÇÃO - INTERCOM, 40, 2017, Curitiba. São Paulo: Intercom, 2017. Disponível em: <http://portalintercom.org.br/anais/nacional2017>. Acesso em: 07 de set. 2020.

ENTERTAINMENT SOFTWARE ASSOCIATION. 2020 Essential Facts About the Video Game Industry. Washington, DC: Entertainment Software Association. 2020. Disponível em: $<$ https://www.theesa.com/wp-content/uploads/2020/07/Final-Edited-2020-ESA_Essential_facts.pdf $>$. Acesso em: 4 set. 2020.

ENTERTAINMENT SOFTWARE ASSOCIATION. 2019 Essential Facts About the Computer and Video Game Industry. Washington, DC: Entertainment Software Association. 2020. Disponível em: $<$ https://www.theesa.com/esa-research/2019-essential-facts-about-the-computer-and-video-game-industry/>. Acesso em: 4 set. 2020. 
EKMAN, Inger. (2005). Understanding Sound Effects in Computer Games [Electronic version]. In Proceedings Digital Arts and Cultures 2005, Kopenhagen, Denmark. Disponível em:

$<$ https://www.researchgate.net/publication/224927551_Meaningful_Noise_Understanding_Sound_Effects_i n_Computer_Games $>$. Acesso em: 2 set. 2020.

FARQUHAR, Dave. Was Atari 2600 8-bit? Kind of. 2018. Disponível em: <https://dfarq.homeip.net/wasatari-2600-8-bit-kind-of/>. Acesso em: 5 set. 2020.

FOX J. A. (2016) 'It's a-me, Mario!' Exploring dynamic changes and similarities in the composition of early Nintendo video game music", Fields: journal of Huddersfield student research. 2(1). doi:

https://doi.org/10.5920/fields.2016.2115

GAL, V.; LE PRADO, C.; MERLAND, J.; NATKIN, S. and VEGA, L. Processes and tools for sound design in computer games, In International Computer Music Conference (ICMC), Gothenburg, Sweden, (2002). Disponível em:

$<$ https://www.researchgate.net/publication/250105724_Processes_and_tools_for_sound_design_in_computer games>. Acesso em: 3 set. 2020.

GÁMEZ, Eduardo; CAIRNS, Paul; COX, Anna. Assessing the core elements of the gaming experience. In: BERNHAUPT, Regina. Game User Experience Evaluation. Toulouse: Springer (part of Springer Science+Business Media), 2015. p. 37-62.

GREENING, Chris. Koji Kondo Biography. 2014. Disponível em: http://www.vgmonline.net/kojikondo/. Acesso em: 05 set. 2020.

HARTSON, Rex; PYLA, Pardha S.. The UX Book: process and guidelines for ensuring a quality user experience. [S. L.]: Morgan Kaufmann Publishers, 2012. 937 p.

HAWKINS, Scott. Indústria de jogos é mais rentável do que as de cinema e música juntas; veja comparação. [Entrevista concedida à redação do F5]. Folha de S. Paulo, 24 de jun., 2020. Disponível em:

$<$ https://f5.folha.uol.com.br/nerdices/2020/06/industria-de-jogos-e-mais-rentavel-do-que-as-de-cinema-emusica-juntas-veja-comparacao.shtml>. Acesso em: 3 set. 2020.

HEINEMAN, David S.. Public Memory and Gamer Identity: Retrogaming as Nostalgia. Journal Of Games Criticism. Troy, p. 1-24. jan. 2014.

HODENT, Celia. The Gamer's Brain: how neuroscience and ux can impact video game design. Boca Raton: Crc Press, 2018. 267 p.

HOROWITZ, Ken. Beyond Donkey Kong: a history of nintendo arcade games. [S. L.]: McFarland, 2020. $273 \mathrm{p}$.

HÖRTNAGL, Jakob. "Why? Because It's Classic!": negotiated knowledge and group identity in the retrogaming community "project 1999”. Medien \& Zeit, Viena, p. 40-49, abr. 2016.

HUNICKE, Robin; LEBLANC, Marc; ZUBEK, Robert. MDA: A Formal Approach to Game Design and Game Research. In: Proceedings of the 19th AAAI Conference, Workshop on Challenges in Game AI. AAAI Press (2004). Disponível em: < https://users.cs.northwestern.edu/ hunicke/MDA.pdf $>$. Acesso em 6 set. 2020.

IIDA, Itiro. Ergonomia: projeto e produção. 2. ed. São Paulo: Blucher, 2005. 
KENT, Steven L.. The Ultimate History of Video Games: Volume Two: from pong to pokemon and beyond...the story behind the craze that touched. Nova York: Crown, 2001. 624 p.

LAZZARO, Nicole. Without Emotion There Is No Game. In: Sears, Andrews; Jacko, Julie. Humancomputer interaction designing for diverse users and domains. Estados Unidos: CRC Press, 2008. p.156-175.

LOGUIDICE, Bill; BARTON, Matt. Vintage games: an insider look at the history of Grand Theft Auto, Super Mario, and the most influential games of all time. Elsevier ( 2009 ) V.1

LUZ, Alan Richard. Vídeo Games: História, Linguagem e Expressão Gráfica. São Paulo: Blucher, 2010.

MAGAIN, Matthew; CHAMBERS, Luke. Get Started in UX: the complete guide to launching a career in user experience design. [S. L.]: Ux Mastery, 2014. 163 p.

MARSH, Tim; COSTELLO, Brigid. Experience in Serious Games: between positive and serious experience. Serious Games Development And Applications, [S.L.], p. 255-267, 2012. Springer Berlin Heidelberg. Disponível em: <http://dx.doi.org/10.1007/978-3-642-33687-4_22>. Acesso em: 3 set. 2020.

MCLERAN, Aaron. Sound and Music In Video Games. [S.1]: Media Arts and Technology Graduate Program. University of California Santa Barbara. 2008. Disponível em:

$<$ http://w2.mat.ucsb.edu/200C/2008_Students/>. Acesso em: 2 set. 2020.

MCMAHAN, Alison. Immersion, engagement and presence: a method for analysing 3-D video games. In: Wolf, Mark; Perron, Bernard. The video game theory reader. London: Routledge, 2003. p. 67-84.

NGUYEN, Jessica. 3D Plataformer and Sound Design in Games.[S.1]: Amsterdam University of Applied Sciences, Department of Computer Science, Amsterdam, 2019.

NORMAN, Donald A. Design emocional: porque adoramos (ou detestamos) os objetos do dia a dia. Rio de Janeiro: Rocco, 2008.

ORTEZA, Wendell. How Sound Effects Affects the Player in Video Games. 2018. 405 f. Dissertação (Mestrado) - Curso de Bachelor Of Arts, Music \& Performing Arts, California State University, Monterey Bay, Monterey, 2018.

PESQUISA GAME BRASIL. Painel Gratuito 2020. [S. L.]: Pesquisa Game Brasil. 2020. Disponível em: $<$ https://materiais.pesquisagamebrasil.com.br/painel-gratuito-2020>. Acesso em: 7 set. 2020.

RIBEIRO, Rennan. Da Cutscene ao Gameplay: A evolução dos recursos narrativos nos videogames. In: NICOLAU, Marcos. Reconfiguração das Práticas Midiáticas na Cibercultura. João Pessoa: Marca de Fantasia, 2012. p. 181-201.

SALEN, Katie; ZIMMERMAN, Eric. Regras do jogo: fundamentos do design de jogos (vol.3). [S. L.]: Editora Blucher, 2012. 258 p.

SANTA-ROSA, J. G., Pereira Junior, A., Lameira, A. P.. Neurodesign: o cérebro e a máquina. 1. ed. Rio de Janeiro: Rio Books, 2016. 166p..

SIRANI, Jordan. Top 10 Best-Selling Video Games of All Time: Minecraft and GTA V Have Dominated the Last Decade, but Where Do They Rank Among the All-Time Bestsellers?. Minecraft and GTA V have dominated the last decade, but where do they rank among the all-time bestsellers?. 2019. 
Disponível em: < https://www.ign.com/articles/2019/04/19/top-10-best-selling-video-games-of-all-time> . Acesso em: 5 set. 2020.

STERNBERG, Robert J.. Psicologia Cognitiva. 4. ed. Porto Alegre: Artmed, 2008. 555 p.

STEVEnS, R., and Raybould, D. 2013. The Game Audio Tutorial: A Practical Guide to Creating and Implementing Sound and Music for Interactive Games. Taylor \& Francis.

SUPERDATA. 2019 Year In Review: Digital Games and Interactive Media. Nova Iorque: Nielsen Company, 2020.(SuperDat report focusing on the health of digital games and interactive media market, breakout moments of 2019 and top trends going into 2020). Disponível em:

$<$ https://www.superdataresearch.com/reports/2019-year-in-review>. Acesso em: 3 set. 2020.

TAYLOR, Brad. NES APU Sound Hardware Reference. 2004b. Disponível em:

$<$ http://www.slack.net/ ant/nes-emu/apu_ref.txt>. Acesso em: 5 set. 2020.

THE MUSHROOM KINGDOM. Sound Clips: Super Mario Bros. (NES). Super Mario Bros. (NES). 2020. Disponível em: <https://themushroomkingdom.net/media/smb/wav>. Acesso em: 28 ago. 2020.

WOLF, Mark, J.P. THE VIDEO GAME EXPLOSION A History from PONG to PlayStation ${ }^{\circledR}$ and Beyond. Greenwood Press Westport, Connecticut: (2008)

WULF, Tim et al. Video Games as Time Machines: Video Game Nostalgia and the Success of Retro Gaming. Media And Communication, Morgantown, v. 6, n. 2, p. 60-68, jun. 2018.

YOUNG, Joshua; MACHERGIANI, Chris. The role of the consumer fanaticism in the acceptance of brand extensions: merchandising in the video games market. School of Marketing, Curtin Business School. Disponível em:

$<$ https://espace.curtin.edu.au/bitstream/handle/20.500.11937/28471/153121_153121.pdf?sequence=2\&isAllo wed=y>. Acesso: 6 set. 2020 .

\section{Agradecimentos}

O presente trabalho foi realizado com apoio da Coordenação de Aperfeiçoamento de Pessoal de Nível Superior - Brasil (CAPES) - Código de Financiamento 001 e foi desenvolvido com apoio do CNPq e da FAPEMA. Agradecemos também à equipe do Núcleo de Prototipagem e Design (Fabrique) do Centro de Ciências Exatas e Tecnologia (CCET) da Universidade Federal do Maranhão (UFMA), à Kátia Raposo pelo apoio e suporte prestado e à Priscilla Bensabath pelas trocas a respeito do tema. 


\section{Apêndice:}

Exemplo de tela do questionário on-line respondido pelos participantes.

Som 1 - Dë play e escute o primeiro som:

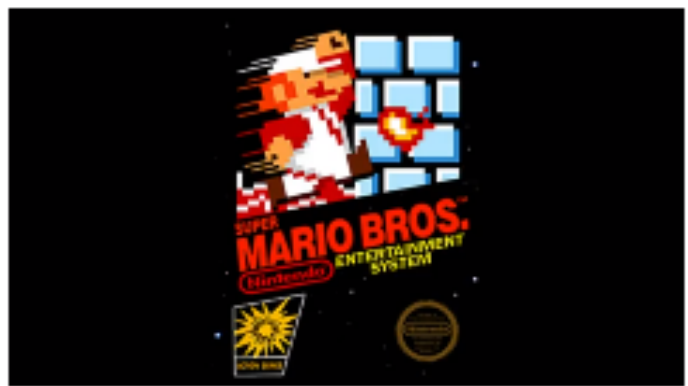

1. Que som é esse?*

Ganhando uma vida

Quebrando o bloco

Batendo a cabeça

Pegando moeda

Soltando bola de fogo

Saltando

Entrando pelo cano

Ficando super

Achando o cogumelo

Amassando os inimigos

Voltar

\section{Próxima}

Nunca envie senhas pelo Formulários Google.

Este conteúdo não foi criado nem aprovado pelo Google. Denunciar abuso - Termos de Serviço- Política de Privacidade

\section{Google Formulários}

